\title{
Endogenously Procyclical Liquidity, Capital Reallocation, and $q$
}

\author{
Melanie Cao \\ York University \\ (mcao@schulich.yorku.ca)
}

\author{
Shouyong Shi \\ Pennsylvania State University \\ (sus67@psu.edu)
}

This version: November $2014^{*}$

\begin{abstract}
By analyzing a stochastic equilibrium with endogenous liquidity in the capital market, this paper explains the puzzling fact that capital reallocation across firms is procyclical while dispersion in Tobin's $q$ across firms is acyclical or counter cyclical. Capital is reallocated across firms through a frictional market modeled by search and matching. The market tightness captures liquidity in this market and is endogenously determined as buyers choose whether to enter the market. Capital creation is also endogenous as capital makers choose whether to incur a cost to make capital. When aggregate productivity increases, more capital is created. At the same time, more buyers enter the capital market to buy capital in an attempt to capture the increased value of a productive firm. As a result, market liquidity increases and more capital is reallocated. The price of capital increases, which increases $q$ of low-value firms and reduces $q$ of high-value firms. The mean and standard deviation in $q$ across firms respond ambiguously to an increase in aggregate productivity. These results are robust to the addition of heterogeneity in firm-specific productivity.
\end{abstract}

Keywords: Endogenous liquidity; Capital reallocation; Tobin's q; Frictions.

* Cao: Finance Area, Schulich School of Business, York University, 4700 Keele Street, Toronto, Ontario, Canada, M3J 1P3. Shi: Department of Economics, Pennsylvania State University, 502 Kern Building, University Park, PA 16802, USA. Cao gratefully acknowledges financial support from the Schulich School of Business, and Shi gratefully acknowledges financial support from the Pennsylvania State University. 


\section{Introduction}

Capital reallocation across firms is large and procyclical. When an economy is in a boom, not only is more new capital created, but also more existing capital is traded across firms. When an economy is in a recession, new investment and the trading of existing capital both fall. Interestingly, procyclical reallocation of capital across firms is not accompanied by procyclical benefits of reallocation. These benefits can be measured by value dispersion across firms, since capital is likely to move from relatively less valuable to more valuable firms. In particular, Tobin's (1969) average $q$, defined as the ratio of the market value to the book value of a firm's assets, exhibits acyclical or counter cyclical dispersion across firms. ${ }^{1}$ In this paper, we construct a model with liquidity frictions in the capital market to show how such liquidity responds positively to aggregate productivity to induce cyclical reallocation of capital and acyclical dispersion in Tobin's $q$.

Endogenous and procyclical liquidity in the capital market seems critical for explaining the above regularities of capital reallocation over the business cycle. To start, it takes more to explain the cyclical pattern of capital reallocation than the cyclical pattern of aggregate investment. In a standard macro theory, shocks to aggregate productivity induce investment to move together with output by increasing the rate of return on capital in a boom and reducing this return in a recession. By itself, this theory would predict counter cyclical reallocation of capital; in particular, when the rate of return on capital is high in a boom, firms should utilize their capital rather than trade capital away. Heterogeneity across firms is necessary for capital reallocation. But such heterogeneity is acyclical or counter cyclical, as described above. Given this lackluster response of the reallocative benefits to the business cycle, the most likely reason why capital reallocation is procyclical is that the

\footnotetext{
${ }^{1}$ Eisfeldt and Rampini (2006) document the facts on capital reallocation. Using Compustat, they find that capital reallocation comprises about one quarter of total investment. The fraction of the capital stock that turns over each year is between $1.4 \%$ and $5.5 \%$, depending on the measure of the capital stock. The correlation of capital reallocation and output is highly positive and significant. The mean allocation rate conditional on GDP above the trend is $59 \%$ higher than the mean allocation rate conditional on GDP below the trend. Also, the cyclical components of dispersion in Tobin's $q$ and GDP have a correlation from -0.130 to 0.134 , depending on the truncation of the data, but no correlation estimate is significantly different from zero. They also compute dispersion in firms' capital utilization rates and dispersion in the sectoral growth of total factor productivity. Both measures of dispersion are significantly counter cyclical.
} 
market for capital reallocation is more liquid in a boom than in a recession. Specifically, if such liquidity increases in a boom, the effective cost of reallocation falls, which stimulates reallocation. Thus, to understand the observed regularities of capital reallocation, it is important to endogenize market liquidity and capture its procyclical movement.

Another motivation for the analysis concerns the role of asset liquidity in business cycles broadly. In the wake of the great recession in 2008-2009, a growing literature has given prominence to financial frictions and asset liquidity. In the majority of this literature, the main driving force is financial shocks that affect either asset liquidity directly or indirectly through the collateral constraint on firms' borrowing (e.g., Kiyotaki and Moore, 2012, and Jermann and Quadrini, 2012). Since financial shocks are exogenous in these models, so are the fluctuations in asset liquidity. As Shi (2013) explains, these models generate counterfactual movements in the equity price - the price rises after a negative financial shock and falls after a positive financial shock. Because asset prices are a main channel through which financial shocks are supposed to affect the aggregate economy, their counter-factual fluctuations are arguably the most undesirable prediction of these models. A promising way to reverse this prediction is to endogenize the fluctuations in asset liquidity as a response to aggregate productivity (including asset quality) so that liquidity can vary procyclically.

In the baseline model here, firms are either productive or displaced, each with one unit of capital. A productive firm faces an idiosyncratic shock of displacement that makes the firm unable to use capital. Such a displaced firm wants to sell capital. Buyers of capital enter the market competitively by paying an entry cost and, after obtaining capital, they become productive. In addition to capital reallocation, new investment is endogenous. Specifically, each capital maker draws a cost of making capital from a distribution and chooses the cut-off cost below which to make capital. The equilibrium endogenously determines the total amount and the distribution of capital between productive and displaced firms.

The frictional capital market is modeled as search and matching. The market tightness, defined as the ratio of buyers to sellers in the market, measures market liquidity because a seller's matching probability increases in the tightness. Liquidity is determined 
endogenously by the entry of buyers. There is dispersion in Tobin's $q$ between firms. We measure the replacement cost of capital by the price of capital, which is determined by Nash bargaining in a match. For any interior bargaining power, the price of capital lies between the values of a displaced firm and a productive firm. Since $q$ is the ratio of firm value to the price of capital, it is higher for a productive firm than for a displaced firm.

We characterize the stochastic equilibrium where aggregate productivity has positive persistence and follows a Markov process. We prove existence of a unique equilibrium. In the equilibrium, the market tightness, the cutoff cost for making capital, the price of capital, and firm values are all increasing functions of the realization of current aggregate productivity. Thus, liquidity, capital reallocation, and capital creation are all procyclical. This procycality arises intuitively from the feature that an increase in aggregate productivity increases the value of a productive firm. Looking forward to this higher value, more buyers enter the capital market, which increases the market tightness and, hence, liquidity. As sellers' matching probability increases, more capital is reallocated across firms. Also, the higher value of a productive firm motivates more capital makers to create capital, resulting in procyclical new investment.

The two types of firms have opposite cyclicality in their $q$. To be more concrete, we examine the case where aggregate productivity is highly persistent, as it is in the data. In this case, the model yields several testable predictions on $q$. First, $q$ is procyclical for firms with relatively low values and counter cyclical for firms with relatively high values. Specifically, a displaced firm's $q$ increases and a productive firm's $q$ decreases in aggregate productivity, for the following reason. When aggregate productivity increases, a displaced firm benefits directly from an increase in the trading probability in addition to an increase in the price of capital. As a result, the value of a displaced firm increases proportionally by more than the price of capital, which makes the firm's $q$ increase with aggregate productivity. In contrast, a productive firm benefits only indirectly from the increased liquidity and price, i.e., in the future when the firm will be displaced. The value of a productive firm increases by less proportionally than does the price of capital, which makes the firm's $q$ counter cyclical. 
Second, the fraction of high-value firms in the economy is procyclical. As higher aggregate productivity increases liquidity, a displaced firm can sell capital more quickly, which results in fewer firms remaining as displaced. Also, higher aggregate productivity increases capital creation, which further increases the flow of firms into the productive group.

Third, the spread in $q$ across firms is counter cyclical, but the standard deviation in $q$ can be either procyclical or counter cyclical. An increase in aggregate productivity reduces the spread in $q$ because it reduces the relatively high $q$ and increases the relatively low $q$. This fall in the spread in $q$ tends to reduce the standard deviation in $q$. However, since the fraction of firms with relatively high $q$ increases in aggregate productivity, this change in the composition of firms tends to increase the standard deviation in $q$. With the two opposite forces, the standard deviation in $q$ respond ambiguously to aggregate productivity.

Most of the results do not rely on the feature that the only heterogeneity across firms is the stark division between productive and displaced firms. To generalize the results, we introduce firm-specific productivity to generate a full distribution of values across productive firms. Despite such heterogeneity, capital liquidity, capital reallocation, capital creation and the price of capital are still procyclical. Now, even within the productive group, a firm's location in the value distribution determines whether the firm's $q$ is procyclical or counter cyclical. Precisely, there exists a cut-off on firm-specific productivity below which a productive firm's $q$ is procyclical and above which a productive firm's $q$ is counter cyclical. Also, the spread and the standard deviation in $q$ across productive firms are counter cyclical. However, the standard deviation of all firms, including displaced firms, still has ambiguous cyclicality.

Furthermore, we allow new firms to choose whether to produce or to sell capital. With this endogenous exit into the displaced group, we show that a reduction in aggregate productivity increases the likelihood that a new firm chooses to sell capital instead of producing, reminiscence of the cleansing effect of recession. With this endogenous exit of productive firms, the spread and the standard deviation in $q$ across productive firms can have ambiguous cyclicality. 
Let us justify the modeling of the capital market as search and matching. In a typical market for capital, trading is not as decentralized as bilateral random matching in our model, but it is also not as centralized as in a Walrasian model where an equilibrium price clears the market quickly. There are substantial frictions in trading, such as asymmetric information regarding asset quality and the cost of finding the suitable asset. This is particularly true in the market for used capital (e.g., Ramey and Shapiro, 2001). These frictions can bring asset trading to a halt sometimes, as in the great recession in 2008-2009. The matching function represents these asset market frictions in a reduced form, as in the macro-labor literature pioneered by Diamond (1982), Mortensen (1982) and Pissarides (1985). Similar modeling has proven to be fruitful for yielding insights about money (see Shi, 1995, Trejos and Wright, 1995), other assets (see Duffie, et al., 2005), and executive compensations (see Cao and Wang, 2013). A prominent feature of a search and matching model is that it captures how the equilibrium price depends on the number of trades, not just on the total quantity traded. As a result, the model provides the market tightness as a direct measure of liquidity.

On endogenous and procyclical liquidity of capital, this paper is related to Eisfeldt (2014). She uses adverse selection to generate liquidity frictions in the capital market and makes the important point that an increase in aggregate productivity can increase market liquidity by increasing the average quality of assets supplied in the market. Complementary to her emphasis on the supply of capital, our model emphasizes the demand by analyzing how an increase in aggregate productivity induces more buyers to participate in the capital market. As said above, the search and matching model also helps link liquidity explicitly to the market tightness. The relatively simple model is tractable and permits many extensions. The model provides a mechanism by which the same force - the disturbance in aggregate productivity - can induce procyclical capital reallocation and capital creation together with acyclical or even counter cyclical dispersion in Tobin's $q$ across firms. Eisfeldt and Rampini (2006) reconcile procyclical reallocation with acyclical dispersion in $q$ by assuming that the marginal cost of reallocation is a decreasing function of aggregate 
productivity. No such assumption is needed in our model. ${ }^{2}$

This paper is also related to the large literature on Tobin's $q$ and adjustment costs in investment, starting with Tobin (1969), Gould (1968), Lucas (1967), and Abel and Blanchard (1986). In a model with irreversible investment, Sargent (1980) clarifies that if shocks to productivity and preferences are both important for business cycles, then there should be no systematic relationship between aggregate investment and Tobin's $q$. Fazzari, et al. (1988) documents that financing constraints seem to explain investment at the micro level much better than $q$, which has led to a debate and on-going effort to reconcile the two determinants of investment. ${ }^{3}$ The frictions in our model are liquidity frictions instead of financing constraints, although the two are not mutually exclusive in general. More importantly, in contrast to this literature, we focus on the cyclical property of capital reallocation and dispersion in $q$ across firms.

We will describe the baseline model in section 2, characterize the equilibrium and cyclical reallocation in section 3 , and examine the cyclicality of $q$ in section 4 . Section 5 will introduce firm-specific productivity. Section 6 will conclude, and the appendices will provide proofs and additional extensions of the model.

\section{Asset Market with Search Frictions}

In this section we describe an economy where all firms that produce have the same productivity. Section 5 will introduce heterogeneity through firm-specific productivity.

\subsection{Environment of the model}

Time is discrete and lasts forever. All individuals and firms in the economy are risk neutral and discount the future at rate $r>0$. There are two types of firms: productive firms and displaced firms. Each firm has one unit of indivisible capital. For a productive firm, capital yields a stream of consumption goods, $y$. This output is common for all productive firms.

\footnotetext{
${ }^{2}$ Yang (2014) and Cui and Radde (2014) also use search and matching models to endogenize asset liquidity. Rather than capital reallocation, they focus on how financial shocks affect asset liquidity.

${ }^{3}$ See Gilchrist and Himmelberg (1995), Gomes (2001), Cooper and Ejarque (2003), Hennessy and Whited (2007), and Cao, et al. (2013).
} 
It is random, and its distribution will be described later. After production, a firm is subject to a displacement shock with probability $\delta$ that makes the firm unable to use capital. The displacement shock is iid across productive firms and over time. Since displaced capital can be productive for another firm, a displaced firm sells capital in the market and exits the economy. For simplicity, we assume that there is a unit capacity constraint on capital, and so a productive firm does not buy additional capital. ${ }^{4}$ Let $j \in\{1,0\}$ denote the type of a firm, where $j=1$ indicates a productive firm and $j=0$ indicates a displaced firm. Let $n_{j}$ be the measure of type- $j$ firms and $V_{j}$ the value of a type- $j$ firm. Both are determined in the equilibrium.

Buyers of capital enter the economy competitively. The entry cost for a buyer is $\psi$ per period. Let $a$ be the measure of buyers entering the market in a period. If a buyer obtains capital, the buyer can start production in the next period.

The capital market suffers from frictions that are modeled as search and matching. Let $\theta$ denote the market tightness, which is the ratio of buyers to sellers (displaced firms). That is, $\theta=a / n_{0}$. A buyer is matched with probability $p(\theta)$, and a seller with probability $\theta p(\theta) .{ }^{5}$ In a match, Nash bargaining determines the price of capital denoted $m$, where the seller's bargaining weight is $\sigma \in(0,1)$. The function $p(\theta)$ is assumed to satisfy: $p \in[0,1]$, $\theta p \in[0,1], p(0)=1, p(\infty)=0,[\theta p(\theta)]_{\theta=\infty}=1,-\frac{p(\theta)}{\theta}<p^{\prime}(\theta)<0$, and $[\theta p(\theta)]^{\prime \prime}<0$. Specifically, the assumption $p^{\prime}<0$ requires intuitively that a buyer's matching probability be strictly decreasing in the relative number of buyers to sellers. The assumption $-\frac{p(\theta)}{\theta}<$ $p^{\prime}(\theta)$ is equivalent to $[\theta p(\theta)]^{\prime}>0$, which requires a seller's matching probability to be strictly increasing in $\theta$. The assumption $[\theta p(\theta)]^{\prime \prime}<0$ requires that increases in $\theta$ generate diminishing marginal gains to a seller's matching probability. Because a seller's matching

\footnotetext{
${ }^{4}$ Caution is needed here. The appropriate interpretation of the unit capacity constraint is that a firm treats different units of its capital stock independently. Thus, a buyer of capital may not necessarily be a new firm in the data, although we will label it so. Instead, the firm can be an existing one that tries to increase its capital stock but calculates the profit of each unit of capital separately. Similarly, a displaced firm may be a firm that experiences displacement on only part of its capital. Thus, the exit of firms from the economy in our model should not be interpreted literally as the exit of firms in the data.

${ }^{5}$ This relationship between the matching probabilities for a buyer and a seller is an implication of constant returns to scale in the matching technology. The latter is assumed since the matching probabilities depend only on the market tightness and not on the number of participants on each side of the market.
} 
probability is an increasing function of $\theta$, more capital is sold in a period if $\theta$ is higher. Thus, we say that the capital market is more liquid if the market tightness is higher.

Search frictions include not only the difficulty of meeting a trading partner but also the specificity of capital. To see this, consider the following generalization of the matching process. After meeting a seller, a buyer is able to adapt the seller's capital to its operation with probability $\zeta$ due to the specificity of capital. A buyer will find a match with suitable capital with probability $\zeta p(\theta)$, and a seller will find a match in which the buyer can adapt the capital with probability $\zeta \theta p(\theta)$. Thus, capital specificity amounts to re-scaling the matching probability function $p(\theta)$.

In addition to capital reallocation across firms, there is capital creation. ${ }^{6}$ In each period, a measure $\mu$ of capital makers can create capital. After the realization of $y$ in a period, a capital maker draws a cost $K$ according to the cumulative distribution function $F$ and decides whether to incur the cost to create a unit of capital. The function $F$ is continuously differentiable. Let $\bar{K}(y)$ be the cut-off cost of capital below which a capital maker chooses to make capital. The measure of newly made capital is $\mu F(\bar{K})$. If a firm foregoes the opportunity to create capital in a period, the firm will have a new draw of the cost in the next period. ${ }^{7}$ Making capital takes the entire period, and so a firm with newly made capital cannot produce in the period in which capital is made. Instead, the firm can start production in the next period.

Capital creation makes the stock of capital grow over time. For capital creation to continue in the equilibrium, some capital must be destroyed; otherwise, the stock of capital will be so large that the profit of creating capital will be negative. For this purpose, we assume that capital experiences a depreciation shock with probability $d<1-\delta$ that destroys capital. If a firm receives the depreciation shock, the firm exits the economy with

\footnotetext{
${ }^{6}$ Allowing for capital creation enables us to show that capital creation is procyclical. Thus, liquidity and reallocation are cyclical not because the economy is unable to change the capital stock in response to productivity shocks.

${ }^{7}$ Heterogeneity in the cost of making capital is realistic, and it is useful for making the equilibrium well behaved. If all capital makers have the same cost, the zero profit condition for such makers and the zero profit condition for buyers' entry will be satisfied only by a measure zero set of parameter values.
} 
value 0 . Every firm with capital is subject to the depreciation shock. ${ }^{8}$ The depreciation shock occurs at the time when the displacement shock occurs, but a firm that produced in the current period does not receive both shocks. Precisely, such a firm receives the displacement shock with probability $\delta$, receives the depreciation shock with probability $d$, and receives no shock with probability $1-\delta-d$. Newly made capital is not subject to the depreciation shock because the capital-making process yields the result after the depreciation shock occurs.

The uncertainty in $y$ is the only aggregate uncertainty in the economy, and the variations in $y$ are called aggregate productivity shocks. Aggregate productivity lies in a compact set $Y$ bounded above zero. Given the current realization $y$, future productivity $y_{+1}$ obeys the transition function $\Phi\left(y_{+1}, y\right)$, where the subscript +1 indicates next period..$^{9} \Phi\left(y_{+1}, y\right)$ is increasing in $y$ if the distribution on $y_{+1}$ given by $\Phi\left(y_{+1}, y_{1}\right)$ first-order stochastically dominates the distribution given by $\Phi\left(y_{+1}, y_{2}\right)$ whenever $y_{1}>y_{2}$. Moreover, $\Phi\left(y_{+1}, y\right)$ strictly increases in $y$ if $\Phi\left(y_{+1}, y\right)$ increases in $y$ for all $y \in Y$ and strictly so in a positively measured subset of $Y$. We impose the following assumption:

Assumption 1. $\Phi\left(y_{+1}, y\right)$ strictly increases in $y$. In addition,

$$
\mathbb{E} y_{+1}>\frac{(r+\delta+d) \psi}{(1-d)(1-\sigma)} \text {. }
$$

where $\mathbb{E}$ is the expectation conditional on the information in the current period.

The assumption that $\Phi\left(y_{+1}, y\right)$ strictly increases in $y$ captures the fact that aggregate productivity is persistent; i.e., if $y$ is high in the current period, then $y_{+1}$ is also likely to be high in the next period. The case of serially independent productivity is treated as the limit case where $\Phi\left(y_{+1}, y\right)$ is independent of $y$. Condition (2.1) requires expected output to

\footnotetext{
${ }^{8}$ Depreciation is caused by not only wear-and-tear in production, but also technological progress that favors a new vintage of capital. This is why the depreciation shock occurs to displaced capital as well as to capital used in production.

${ }^{9} \mathrm{~A}$ function $\Phi$ is a transition function if for any given $y, \Phi\left(y_{+1}, y\right)$ is a probability distribution function on $y_{+1}$ and, for any given $y_{+1}, \Phi\left(y_{+1}, y\right)$ is a continuous function of $y$. We impose the standard assumption that $\Phi$ has the Feller property (see Stokey, et al., 1989); i.e., $\int f\left(y_{+1}, y\right) \Phi\left(\mathrm{d} y_{+1}, y\right)$ is continuous in $y$ whenever $f$ is continuous.
} 
be sufficiently high relative to the entry cost of a buyer. As explained later, this condition is needed for a positive measure of buyers to participate in the capital market.

The focus of this paper is on how the equilibrium responds to aggregate productivity shocks. A variable is procyclical if it varies in the same direction as $y$, counter cyclical if it varies in the opposite direction to $y$, and acyclical if it does not vary with $y$. In particular, capital market liquidity is procyclical if $\theta$ is an increasing function of aggregate productivity, and capital creation is procyclical if the cut-off cost of making capital, $\bar{K}$, is an increasing function of aggregate productivity.

The timing of events in a period is as follows:

(i) The distribution of firms, $n=\left(n_{1}, n_{0}\right)$, is measured;

(ii) $y$ is realized and but output is not produced yet;

(iii) A buyer decides whether to incur the $\operatorname{cost} \psi$ to enter the market, and a capital maker draws a cost $K$ and decides whether to incur the cost to make capital;

(iv) Trading takes place in the capital market and productive firms produce, while capital makers start capital creation but the process does not complete until later;

(v) Old capital is subject to the depreciation shock, and a firm that just produced is also subject to the displacement shock;

(vi) Capital creation is completed, after which firm values, $\left(V_{1}, V_{0}\right)$, are measured.

Several aspects of this timing simplify the equations. We assume that aggregate productivity is realized at the beginning of the period so that firms can use the realization to calculate the payoffs. Production takes time and takes place at the same time as trading in the capital market. Thus, after buying capital, a buyer can start production no earlier than the next period. Similarly, since the displacement shock occurs after the capital market is already closed, a newly displaced firm can sell capital no earlier than the next period. Also, newly bought capital is not subject to displacement in the same period. 


\subsection{Value functions}

The value of a type- $j$ firm is $V_{j}$. Although $V_{j}$ is measured at the end of a period, it is convenient to write it as a function of the aggregate state at the beginning of the period. This aggregate state is described by the distribution of firms, $n=\left(n_{1}, n_{0}\right)$, and the realization of aggregate productivity, $y$. Thus, $V_{j}=V_{j}(n, y)$. To economize on the notation, we suppress the dependence of the variables on the aggregate state whenever there is no confusion.

Consider a capital maker immediately after drawing a cost $K$ in a period. If the capital maker incurs the cost, a unit of new capital will emerge before the period ends, and the value will be $V_{1}$. It is optimal for the capital maker to make capital if and only if $K<V_{1}$. Thus, the cut-off cost below which a capital maker chooses to make capital is

$$
\bar{K}=V_{1}
$$

Now consider a buyer at the point of choosing whether to enter the capital market. If the buyer enters the market, the cost is $\psi$ in the period. With probability $p$, the buyer will be matched with a seller and will pay price $m$ to get a unit of capital. If the newly bought capital escapes depreciation, which occurs with probability $(1-d)$, its value at the end of the period will be $V_{1}$. Thus, the buyer's surplus of trade is $\left[(1-d) V_{1}-m\right]$, and the buyer's expected surplus in the market is $p\left[(1-d) V_{1}-m\right]$. Because entry is competitive, this expected surplus must be equal to the entry cost; i.e.,

$$
p\left[(1-d) V_{1}-m\right]=\psi
$$

Note that the residual value for a buyer who fails to trade is zero. A buyer must pay the entry cost $\psi$ in each period to stay in the market.

Turn to a displaced firm at the end of a period at which time $V_{0}$ is measured. In the next period, the firm will go to the capital market to sell capital. The firm will be matched with a buyer with probability $\theta_{+1} p_{+1}$, where $p_{+1}=p\left(\theta_{+1}\right)$. In this case, the firm will sell capital at price $m_{+1}$ and exit the economy. Normalize the value of exiting to zero. If the firm fails to trade, the firm's value will be $(1-d) V_{0,+1}$, because 
unsold capital will also be subject to depreciation. Thus, the firm's surplus of trade in the next period will be $\left[m_{+1}-(1-d) V_{0,+1}\right]$, and the expected surplus in the market will be $\theta_{+1} p_{+1}\left[m_{+1}-(1-d) V_{0,+1}\right]$. A displaced firm's value function obeys:

$$
(1+r) V_{0}=\mathbb{E}\left\{\theta_{+1} p_{+1}\left[m_{+1}-(1-d) V_{0,+1}\right]+(1-d) V_{0,+1}\right\}
$$

The value function on the left-hand side is multiplied by $(1+r)$ because $V_{0}$ is measured at the end of the period, which implies that all returns on the right-hand side are future returns that must be discounted by $(1+r)$.

A firm that is type- 1 at the end of a period will start the next period with the ability to produce. Because production takes time, the firm will not participate in the capital market in the next period. At the end of the next period, the firm will be displaced with probability $\delta$, in which case the firm's value will be $V_{0,+1}$. The firm's capital will depreciate with probability $d$, in which case the firm's value will be 0 . And the firm will remain productive with probability $(1-\delta-d)$, in which case the firm's value will be $V_{1,+1}$. Thus, a productive firm's value function satisfies

$$
(1+r) V_{1}=\mathbb{E}\left[y_{+1}+(1-\delta-d) V_{1,+1}+\delta V_{0,+1}\right]
$$

\subsection{Bargaining}

Consider a match between a buyer and a seller in the capital market. The two bargain over the price of capital, $m$. A trade at price $m$ gives the surplus $\left[(1-d) V_{1}-m\right]$ to the buyer and the surplus $\left[m-(1-d) V_{0}\right]$ to the seller. The price $m$ maximizes the product of the weighted surpluses of the two sides:

$$
\max _{m}\left[m-(1-d) V_{0}\right]^{\sigma}\left[(1-d) V_{1}-m\right]^{1-\sigma},
$$

where $\sigma \in[0,1]$ is the seller's bargaining weight. The solution is

$$
m=(1-d)\left[\sigma V_{1}+(1-\sigma) V_{0}\right]
$$

The joint surplus of the match is $(1-d)\left(V_{1}-V_{0}\right)$. At the price in $(2.6)$, the seller gets a share $\sigma$ of the joint surplus of the match and the buyer gets a share $(1-\sigma)$. 


\section{Market Equilibrium}

\subsection{Definition of the equilibrium}

The flows of firms are depicted below. The expression above or beside an arrow is the probability of the flow indicated by the arrow. The measure of the flow is the flow probability multiplied by the measure of firms at the origin of the arrow. These flows generate the following dynamics in the distribution of firms:

$$
\begin{aligned}
& n_{1,+1}-n_{1}=(1-d) \theta p n_{0}+\mu F(\bar{K})-(\delta+d) n_{1} \\
& n_{0,+1}-n_{0}=\delta n_{1}-[\theta p+(1-\theta p) d] n_{0}
\end{aligned}
$$

where we have substituted $a=\theta n_{0}$. For example, there are two inflows into productive firms. One is the buyers who succeed in trade and escape depreciation, the size of which is $(1-d) \theta p n_{0}$. The other is capital makers who choose to make capital, the size of which is $\mu F(\bar{K})$. The flow out of productive firms is $(\delta+d) n_{1}$, which is generated by displacement and depreciation. The net change in the measure of productive firms is the difference between the inflow and the outflow.

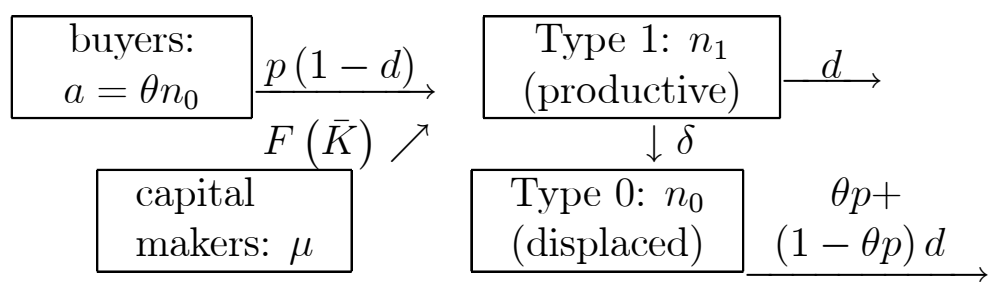

The equilibrium of the economy consists of the value functions $\left(V_{j}(n, y)\right)_{j=1,0}$, the distribution of firms $\left(n_{j}\right)_{j=1,0}$, the capital-making decision represented by the cut-off cost $\bar{K}(n, y)$, the market tightness $\theta(n, y)$, and the price of capital $m(n, y)$ such that the following requirements are met: the cut-off $\bar{K}$ satisfies (2.2); the entry of buyers satisfies (2.3); the value functions satisfy (2.4)-(2.5); the price of capital satisfies (2.6); and the distribution of firms satisfies (3.1).

\subsection{Existence of the equilibrium and procyclical liquidity}

To determine the equilibrium, let us denote the joint surplus of a match as $\Delta \equiv V_{1}-V_{0}$. Denote the inverse function of $p(\theta)$ as $p^{-1}$. It is clear from (2.3) and (2.6) that the market 
tightness can be written as a function of $\Delta$ :

$$
\theta=\theta(\Delta) \equiv p^{-1}\left(\frac{\psi}{(1-d)(1-\sigma) \Delta}\right)
$$

Subtracting (2.4) from (2.5), substituting $m$ from (2.6) and substituting $\theta=\theta(\Delta)$, we get

$$
\Delta=\frac{1}{1+r} \mathbb{E}\left\{y_{+1}+(1-\delta-d) \Delta_{+1}-\frac{\sigma \psi}{1-\sigma} \theta\left(\Delta_{+1}\right)\right\}
$$

This is a functional equation of $\Delta$. After solving $\Delta$ from this equation, we can find $\theta$ from (3.2), $\left(V_{0}, V_{1}\right)$ from (2.4) and (2.5), and $\bar{K}$ from (2.2). Moreover, after substituting $(\theta, \bar{K})$, the two equations in (3.1) determine the dynamic path of $n=\left(n_{1}, n_{0}\right)$. Thus, determining an equilibrium amounts to finding a solution to (3.3) for the function $\Delta(n, y)$.

The function $\Delta(n, y)$ is expected to lie in $\mathcal{C}$, the set that contains all continuous functions on $[0,1]^{2} \times Y$. The following proposition states the existence and other properties of the equilibrium (See Appendix A for a proof):

Proposition 3.1. Maintain Assumption 1. If there exists a constant $A>0$ such that

$$
\begin{aligned}
& A \leq \frac{1-\delta-d}{(1-d) \sigma} \\
& \left|p^{-1}\left(x_{1}\right)-p^{-1}\left(x_{2}\right)\right| \leq A\left|\frac{1}{x_{1}}-\frac{1}{x_{2}}\right| \text { for all } x_{1}, x_{2} \in[0,1]
\end{aligned}
$$

then there exists a unique function $\Delta \in \mathcal{C}$ that solves (3.3), and so a unique equilibrium exists. The equilibrium has the following properties: (i) $\Delta>\frac{\psi}{(1-d)(1-\sigma)}$ and $\theta>0$; (ii) $\Delta$ is independent of $n$ and, hence, can be written as $\Delta(y)$; (iii) $\Delta(y)$ is strictly increasing in $y$; (iv) The market tightness $\theta$, the value functions $\left(V_{0}, V_{1}\right)$, the price of capital $m$ and the cutoff cost $\bar{K}$ are all strictly increasing functions of $y$, and are independent of $n$.

Conditions (3.4) and (3.5) together ensure that the mapping on $\Delta$ defined by the righthand side of (3.3) is a monotone contraction. ${ }^{10}$ In addition, (3.5) is used to ensure that

\footnotetext{
${ }^{10}$ If these conditions are violated, it may be possible that an increase in future output $y_{+1}$ increases the market tightness $\theta_{+1}$ by so much that the induced increase in $V_{0,+1}$ exceeds that of $V_{1,+1}$. In this case, $\Delta_{+1}$ falls after an increase in $y_{+1}$, and so the mapping defined by the right-hand side of (3.3) may fail to be montone or to map increasing functions into increasing functions.
} 
$\theta($.$) is a continuous function, which is needed for the right-hand side of (3.3) to map$ continuous functions into continuous functions. Property (i) in the proposition relies on (2.1) in Assumption 1. To see why (2.1) is needed for $\theta>0$, note that a productive firm's output stream is terminated if the firm experiences displacement or depreciation. Thus, the firm's effective discount rate is $(r+\delta+d)$, and the expected present value of output is $\frac{\mathbb{E} y+1}{r+\delta+d}$. Because newly bought capital is subject to displacement before the buyer starts to produce, the present value of future output at the time of trading is $\frac{(1-d) \mathbb{E} y+1}{r+\delta+d}$. Condition (2.1) requires a buyer's share of this present value of output to be greater than the entry cost so that a positive measure of buyers choose to enter the capital market.

The fixed point $\Delta$ is independent of $n$ because, for any given $\Delta_{+1}$, the right-hand side of (3.3) does not depend on $n$. Starting with any function $\Delta$ independent of $n$, the sequence of functions obtained by applying the mapping defined by the right-hand side of (3.3) on the function converges to a fixed point $\Delta(y)$ that is independent of $n$. Because this mapping is a monotone contraction, $\Delta(y)$ is the unique fixed point even if one starts with a function dependent on $n$. As a result, $\left(\theta, V_{0}, V_{1}, m, \bar{K}\right)$ are all independent of $n$.

It is noteworthy to explain more generally why the value functions, the tightness, the price of capital and the cut-off cost for capital creation are all independent of the distribution of firms in the equilibrium. The general causes of this property are constant returns to scale in the matching function and competitive entry of buyers. Because the matching function has constant returns to scale, the only channel through which the distribution of firms can affect the value functions is the market tightness. With competitive entry of buyers, the market tightness must ensure zero profit for a buyer. This requirement determines the market tightness as only a function of the joint surplus of a match that, in turn, depends only on the value functions but not on the distribution of firms. As a result, the value functions are determined independently of the distribution of firms. So are the market tightness, the price of capital and the cut-off cost for capital creation.

Capital market liquidity and capital reallocation are procyclical in the equilibrium. This is clear because market tightness $\theta$ is an increasing function of $\Delta$, as determined 
by (3.2), and $\Delta$ is an increasing function of $y$ by Proposition 3.1. Procyclical liquidity in the capital market is intuitive. Since aggregate productivity is persistent, an increase in aggregate productivity indicates higher future productivity and, hence, a higher value of a firm that enters the next period with productive capital. This means that the joint surplus of a match in the current period is higher. Because a buyer gets a fraction of the joint surplus, the return to participating in the market increases for a buyer. This higher return induces more buyers to enter in the current period, which increases a seller's matching probability. The entry of more buyers restores the equilibrium by reducing a buyer's matching probability so that the expected surplus to a buyer in the market is equal to the entry cost. ${ }^{11}$ Because market liquidity is procyclical, the values of all firms are procyclical. So is the price of capital.

Capital creation is also procyclical in the equilibrium. This is evident from (2.2) and the result that $V_{1}(y)$ is an increasing function. An increase in aggregate productivity increases the cut-off cost below which a potential capital maker chooses to make capital. The measure of newly made capital, $\mu F(\bar{K})$, increases. Therefore, the liquidity, the reallocation, and the creation of capital are all procyclical in the equilibrium.

We give two examples to illustrate that (3.4) and (3.5) can be satisfied:

Example 3.2. Consider the matching function that determines the number of matches in a period as $\frac{n_{0} a}{\left(n_{0}^{\gamma}+a^{\gamma}\right)}$, where $\gamma \in(0,1]$. In the special case $\gamma=1$, this matching function becomes the so-called telegraph matching function. For all $\gamma \in(0,1], p(\theta)=\left(\theta^{\gamma}+1\right)^{-1 / \gamma}$, and so $\frac{1}{p}=\left(\theta^{\gamma}+1\right)^{1 / \gamma} \equiv g(\theta)$. It is clear that $g^{\prime}(\theta)=\left(\theta^{-\gamma}+1\right)^{\frac{1}{\gamma}-1}>0$. Also, $g^{\prime \prime}(\theta)=0$ if $\gamma=1$, and $g^{\prime \prime}(\theta)<0$ if $\gamma \in(0,1)$. Thus, for any $x_{1}, x_{2} \in[0,1]$, and $\theta_{i}=p^{-1}\left(x_{i}\right)$ for $i=1,2$, the following is true:

$$
\left|\frac{1}{x_{1}}-\frac{1}{x_{2}}\right|=\left|g\left(\theta_{1}\right)-g\left(\theta_{2}\right)\right| \geq g^{\prime}(\infty)\left|\theta_{1}-\theta_{2}\right| .
$$

Because $g^{\prime}(\infty)=1,(3.5)$ is satisfied with $A=1$, in which case (3.4) requires $\sigma<1-\delta$.

\footnotetext{
${ }^{11}$ Because of the assumption that a buyer can start producing with the newly bought capital no earlier than the next period, a higher $y$ can affect the match surplus in the current period only by increasing the expectation of future productivity. Mathematically, for the mapping defined by the right-hand side of (3.3) to map increasing functions into strictly increasing functions, $\Phi\left(y_{+1}, y\right)$ needs to be increasing in $y$. If $\Phi\left(y_{+1}, y\right)$ is independent of $y$, instead, then liquidity is independent of $y$.
} 
Example 3.3. Consider the matching function that determines the number of matches in a period as $n_{0}\left(1-e^{-a / n_{0}}\right)$. This is the so-called urn-ball matching function where the sellers are the urns and the buyers balls. This matching function implies $p(\theta)=\frac{1-e^{-\theta}}{\theta}$, and so $\frac{1}{p}=\frac{\theta}{1-e^{-\theta}} \equiv g(\theta)$. Since $g^{\prime}(\theta)>0$ and $g^{\prime \prime}(\theta)>0$, then $\left|g\left(\theta_{1}\right)-g\left(\theta_{2}\right)\right| \geq g^{\prime}(0)\left|\theta_{1}-\theta_{2}\right|$. Because $g^{\prime}(0)=\frac{1}{2},(3.5)$ is satisfied with $A=2$, in which case (3.4) requires $\sigma<\frac{1-\delta}{2}$.

\section{Cyclicality of Tobin's $q$}

In the original definition, Tobin's (1969) $q$ is the ratio of the market value of a firm to the replacement cost of capital. In practice, $q$ is usually measured as the ratio of the market value to the book value of a firm. In our model, the market value of a type- $j$ firm is $V_{j}$, where $j \in\{1,0\}$. The model offers two ways to measure the replacement cost of capital. One is the cost of making capital, $K$, and the other is the price of capital, $m$. However, the cost of making capital is not a convenient measurement of the replacement cost. There is heterogeneity in this cost across firms and, even for any given firm, the cost of making capital varies over time because it is a random draw each time. Although the expected cost of making capital can be used as a uniform measure of the replacement cost of capital, it is unlikely to be observable in the data. In contrast, the market price of capital, $m$, is observable and uniform across firms. In addition, this price is what a firm can pay to get a unit of capital. For these reasons, we use $m$ as the replacement cost of capital and define a type- $j$ firm's $q$ as ${ }^{12}$

$$
q_{j} \equiv \frac{V_{j}}{m}, \quad j \in\{1,0\}
$$

Because $\Delta>0$, as shown in Proposition 3.1, then $q_{1}>\frac{1}{1-d}>q_{0}$. The spread in $q$ between the two types of firms is $\left(q_{1}-q_{0}\right)$. Since (2.6) implies $\sigma q_{1}+(1-\sigma) q_{0}=\frac{1}{1-d}$, then

$$
q_{0}=\frac{1}{1-d}-\sigma\left(q_{1}-q_{0}\right)=\frac{V_{0} / \Delta}{(1-d)\left[\sigma+V_{0} / \Delta\right]}
$$

Note that $q_{j}$ is a function of $y$. The following result follows from (4.1):

\footnotetext{
${ }^{12}$ Because each firm is assumed to have one unit of capital, the average $q$ of a firm is equal to the marginal $q$ in this model.
} 
Corollary 4.1. $q_{1}(y)$ and $\left[q_{1}(y)-q_{0}(y)\right]$ are decreasing functions if and only if $q_{0}(y)$ is an increasing function. Moreover, $q_{0}(y)$ is an increasing function if and only if $\frac{V_{0}(y)}{\Delta(y)}$ is.

The two types of firms have opposite cyclical properties in $q$ because the sum of the two $q$ 's, weighted by $(\sigma, 1-\sigma)$, is equal to the constant, $\frac{1}{1-d}$. The spread in $q$ between the two types of firms varies with aggregate productivity in the same way as a productive firm's $q$ and, hence, opposite to a displaced firm's $q$, since $q_{1}-q_{0}=\left(\frac{1}{1-d}-q_{0}\right) / \sigma$. Moreover, because the price of capital is $(1-d)\left(V_{0}+\sigma \Delta\right)$, this price increases with aggregate productivity by less proportionally than $V_{0}$ does if and only if the joint surplus $\Delta$ increases with aggregate productivity by less proportionally than $V_{0}$ does. Thus, $q_{0}$ increases with $y$ if and only if $\left(V_{0} / \Delta\right)$ does. Note that $\frac{V_{1}}{\Delta}$ has the same cyclical property as $\frac{V_{0}}{\Delta}$, because $\frac{V_{1}}{\Delta}=1+\frac{V_{0}}{\Delta}$. Thus, $q_{1}$ has the opposite cyclical property to $\frac{V_{1}}{\Delta}$.

It is ambiguous in general which of the two q's is procyclical. To gain insights, we appeal to the fact that aggregate productivity is highly persistent. We examine the $q$ 's in the deterministic steady state and then use an example to illustrate that the properties of the steady state are shared by the stochastic equilibrium when aggregate productivity is highly persistent. Before embarking on these tasks, let us define the mean and the standard deviation in $q$ in general. Recall that $V_{j}$ is measured at the end of a period. At such a point of time, the distribution of firms is $\left(n_{1,+1}, n_{0,+1}\right)$ instead of $\left(n_{1}, n_{0}\right)$. Denote the mean of $q$ across firms as $E q$, and the standard deviation as $S_{q}$. Using the distributions of firms corresponding to $\left(V_{1}, V_{0}\right)$, we can calculate

$$
\begin{aligned}
& E q=\frac{n_{1,+1} q_{1}+n_{0,+1} q_{0}}{n_{1,+1}+n_{0,+1}}, \\
& S_{q}=\left[\frac{n_{1,+1}}{n_{1,+1}+n_{0,+1}}\left(1-\frac{n_{1,+1}}{n_{1,+1}+n_{0,+1}}\right)\right]^{1 / 2}\left(q_{1}-q_{0}\right) .
\end{aligned}
$$

Because the value of the market portfolio per firm at the end of a period is $\frac{n_{1,+1} V_{1}+n_{0,+1} V_{0}}{n_{1,+1}+n_{0,+1}}$, it is easy to see that $E q$ is also the $q$ of this market portfolio per firm.

Consider the deterministic steady state of the economy, which is indicated by the superscript $*$. In this steady state, aggregate productivity in the steady state is $y^{*}$, and 
$\left(\theta^{*}, \Delta^{*}, V_{0}^{*}, \bar{K}^{*}, V_{0}^{*} / \Delta^{*}, n_{1}^{*}, n_{0}^{*}\right)$ are determined as follows:

$$
\begin{aligned}
& \sigma \theta^{*}+\frac{r+\delta+d}{(1-d) p\left(\theta^{*}\right)}=(1-\sigma) \frac{y^{*}}{\psi}, \quad \Delta^{*}=\frac{\psi}{(1-d)(1-\sigma) p^{*}}, \\
& V_{0}^{*}=\frac{\sigma \psi}{(1-\sigma)(r+d)} \theta^{*}, \quad \bar{K}^{*}=V_{1}^{*}=V_{0}^{*}+\Delta^{*}, \quad \frac{V_{0}^{*}}{\Delta^{*}}=\frac{1-d}{r+d} \sigma \theta^{*} p^{*}, \\
& n_{1}^{*}=\frac{\mu F\left(\bar{K}^{*}\right)\left[d+\theta^{*} p^{*}(1-d)\right]}{d\left[\delta+d+\theta^{*} p^{*}(1-d)\right]}, \quad n_{0}^{*}=\frac{\delta \mu F\left(\bar{K}^{*}\right)}{d\left[\delta+d+\theta^{*} p^{*}(1-d)\right]} .
\end{aligned}
$$

The following proposition follows from differentiating the equations in (4.2):

Proposition 4.2. Assume $y^{*}>\frac{(r+\delta+d) \psi}{(1-d)(1-\sigma)}$. The deterministic steady state satisfies:

$$
\begin{aligned}
& \frac{d \Delta^{*}}{d y^{*}}>0, \frac{d \theta^{*}}{d y^{*}}>0, \frac{d V_{0}^{*}}{d y^{*}}>0, \frac{d V_{1}^{*}}{d y^{*}}=\frac{d \bar{K}^{*}}{d y^{*}}>0, \frac{d m^{*}}{d y^{*}}>0 \\
& \frac{d n_{1}^{*}}{d y^{*}}>0, \frac{d}{d y^{*}}\left(\frac{n_{1}^{*}}{n_{0}^{*}}\right)>0, \frac{d q_{0}^{*}}{d y^{*}}>0, \frac{d q_{1}^{*}}{d y^{*}}<0, \frac{d\left(q_{1}^{*}-q_{0}^{*}\right)}{d y^{*}}<0 .
\end{aligned}
$$

The signs of $\frac{d\left(E q^{*}\right)}{d y^{*}}$ and $\frac{d S_{q}^{*}}{d y^{*}}$ are ambiguous. A sufficient condition for $\frac{d\left(E q^{*}\right)}{d y^{*}}>0$ is $\frac{n_{1}^{*}}{n_{1}^{*}+n_{0}^{*}}<\sigma$, and a sufficient condition for $\frac{d S_{q}^{*}}{d y^{*}}<0$ is $n_{1}^{*} \geq n_{0}^{*}$.

The assumption $y^{*}>\frac{(r+\delta+d) \psi}{(1-d)(1-\sigma)}$ is the deterministic version of $(2.1)$, which is required for a positive measure of buyers to enter the capital market. The properties of $\left(\Delta^{*}, \theta^{*}, V_{0}^{*}, V_{1}^{*}, \bar{K}^{*}, m^{*}\right)$ in (4.3) are analogous to properties (iii) and (iv) in Proposition 3.1. In the steady state, the measure of productive firms is an increasing function of the matching probability for a seller, $\theta^{*} p^{*}$, and the cut-off $\bar{K}^{*}$ (see (4.2)). Since the latter two increase in aggregate productivity, so does the measure of productive firms in the steady state. Intuitively, as a higher $y^{*}$ increases the number of buyers in the capital market, induces capital to be sold more quickly and, hence, takes more firms out of the displaced group and into the productive group. In addition, a higher $y^{*}$ induces more firms to create new capital, which further increases the measure of productive firms. As more capital is made in the steady state when $y^{*}$ is higher, the total measure of firms also increases in aggregate productivity. The measure of displaced firms may increase or decrease in aggregate productivity. While the increase in the measure of productive firms increases the measure of displaced firms, the increased liquidity makes displaced firms exit more quickly. 
Regardless of whether the measure of displaced firms increases, the ratio of productive firms to displaced firms increases in aggregate productivity.

In the steady state, a displaced firm's $q$ increases with aggregate productivity. With Corollary 4.1, this result implies that as aggregate productivity increases in the steady state, a productive firm's $q$ decreases, the spread in $q$ between the two types of firms decreases, and the ratio $V_{0}^{*} / \Delta^{*}$ increases. The reason why higher aggregate productivity increases a displaced firm's $q$ in the steady state is that it increases capital market liquidity. Intuitively, as liquidity increases, a displaced firm benefits directly from a higher matching probability in addition to the higher price of capital. As a result, the value of a displaced firm increases by more proportionally than does the price of capital, resulting in a higher $q$ for a displaced firm. In contrast, a productive firm benefits from the higher liquidity and higher price only indirectly, i.e., in the future when the firm will be displaced. Because these benefits are indirect, the induced increase in a productive firm's value is less proportionally than the increase in the price of capital, resulting in a lower $q$ for a productive firm in the steady state.

The link between $q_{0}^{*}$ and $\theta^{*}$ can be confirmed by (4.2), which shows that $V_{0}^{*} / \Delta^{*}$ is proportional of $\theta^{*} p\left(\theta^{*}\right)$, the matching probability of a seller in the capital market. This simple expression for $V_{0}^{*} / \Delta^{*}$ comes from the results that the value of a displaced firm in the steady state is proportional to the market tightness and that the joint surplus of a match is proportional to $1 / p$. Because a seller's matching probability increases in $\theta^{*}$, and $\theta^{*}$ increases in $y^{*}$, then $V_{0}^{*} / \Delta^{*}$ increases in $y^{*}$. By Corollary 4.1, $q_{0}$ responds to $y$ in the same way as $V_{0} / \Delta$ does. Thus, $q_{0}^{*}$ increases in $y^{*}$ because the market tightness increases in aggregate productivity. ${ }^{13}$

Because the two $q$ 's respond to aggregate productivity in opposite directions, the mean and the standard deviation in $q$ depend ambiguously on aggregate productivity. Adding to this ambiguity is the response of the distribution of firms between the two types to aggregate productivity. When aggregate productivity increases, the increases in a displaced firm's $q$

\footnotetext{
${ }^{13}$ Unfortunately, this intuitive explanation for the steady state does not extend to the stochastic equilibrium in general, because $V_{0}$ is not proportional to $\theta$ in the stochastic equilibrium.
} 
and in the fraction of productive firms tend to increase the mean of $q$, but the reduction in a productive firm's $q$ reduces the mean. The mean of $q$ increases in aggregate productivity if the fraction of productive firms is not too large, and a sufficient condition for this outcome is $n_{1}^{*} /\left(n_{1}^{*}+n_{0}^{*}\right)<\sigma$. By reducing a productive firm's $q$ and increasing a displaced firm's $q$, an increase in aggregate productivity reduces the spread in $q$ between the two types of firms. The standard deviation in $q$ is equal to the spread in $q$ multiplied by a function of $\frac{n_{1}^{*}}{n_{1}^{*}+n_{0}^{*}}\left(1-\frac{n_{1}^{*}}{n_{1}^{*}+n_{0}^{*}}\right)$. When a half or more firms are productive, this multiplier decreases in $n_{1}^{*}$ and, hence, in $y^{*}$. This effect reinforces the reduction in the spread in $q$ to reduce the standard deviation in $q$ in the steady state when aggregate productivity increases.

We use an example to illustrate that the above features of the deterministic steady state carry over to the stochastic equilibrium if aggregate productivity is sufficiently persistent.

Example 4.3. Consider $p(\theta)=\frac{1}{1+\theta}$ (the special case $\gamma=1$ of the matching function in Example 3.2) and a process of $y$ that satisfies:

$$
\mathbb{E} y_{+1}=(1-\rho) y^{*}+\rho y, \quad \rho \in(0,1], \text { where } y^{*}>\frac{(r+\delta+d) \psi}{(1-d)(1-\sigma)} .
$$

The specification (4.5) encompasses some well-known processes as special cases. One such case is the AR(1) process. Another special case is the Markov process where $y$ has two realizations, $\left(y_{1}, y_{2}\right)$. In this case, the transition probabilities are $\operatorname{Pr}\left(y_{+1}=y_{i} \mid y=y_{i}\right)=\frac{1+\rho}{2}$ and $\operatorname{Pr}\left(y_{+1}=y_{-i} \mid y=y_{i}\right)=\frac{1-\rho}{2}$ for $i \in\{1,2\}$, where $-i \neq i$. The unconditional mean of $y$ is $y^{*}=\frac{y_{1}+y_{2}}{2}$.

With $p(\theta)$ in the above example, (3.2) yields $\theta(\Delta)=(1-d)(1-\sigma) \frac{\Delta}{\psi}-1$. The functional equations, (3.3) and (2.4), simplify to

$$
\begin{aligned}
& \Delta=\frac{1}{1+r} \mathbb{E}\left\{y_{+1}+\frac{\sigma \psi}{1-\sigma}+[(1-d)(1-\sigma)-\delta] \Delta_{+1}\right\} \\
& V_{0}=\frac{1}{1+r} \mathbb{E}\left[\sigma(1-d) \Delta_{+1}-\frac{\sigma \psi}{1-\sigma}+(1-d) V_{0,+1}\right] .
\end{aligned}
$$

We have the following proposition (see Appendix B for a proof):

Proposition 4.4. If $p(\theta)$ and the process of $y$ are given in Example 4.3, then $\Delta$ and $V_{0}$ are solved as

$$
\Delta(y)=b_{0}+b_{1} y, \quad V_{0}(y)=c_{0}+c_{1} y,
$$


where $\left(b_{0}, b_{1}, c_{0}, c_{1}\right)$ are given in Appendix B. There exists $\underline{\rho} \in(0,1)$ such that $q_{0}^{\prime}(y)>0$ and, hence, $q_{1}^{\prime}(y)<0$ if and only if $\rho>\underline{\rho}$. Moreover, $\underline{\rho} \rightarrow 0$ when $y^{*} \rightarrow \frac{(r+\delta+d) \psi}{(1-d)(1-\sigma)}$, and $\underline{\rho} \rightarrow 1$ when $r+d \rightarrow 0$.

The parameter $\rho$ is the persistence of aggregate productivity. When this persistence exceeds the critical level $\underline{\rho}$, a displaced firm's $q$ is procyclical and a productive firm's $q$ is counter cyclical. The critical level $\underline{\rho}$ depends on most parameters in the model and, in particular, on $y^{*}$ and $(r+d)$. When the unconditional mean of aggregate productivity approaches the lower bound, $\frac{(r+\delta+d) \psi}{(1-d)(1-\sigma)}$, the critical level $\underline{\rho}$ approaches zero. In this case, a displaced firm's $q$ is procyclical as long as aggregate productivity has some persistence. The reason is that the market tightness and the value of a displaced firm approach zero when $y^{*}$ approaches the lower bound. From this base value close to zero, an increase in the value of a displaced firm caused by an increase in $y$ results in a large proportional increase. This proportional increase is larger than the proportional increase in the price of capital. On the other hand, when $(r+d)$ goes to zero, the critical level $\underline{\rho}$ approaches zero. In this case, a displaced firm's $q$ is counter cyclical unless aggregate productivity is permanent. The reason is that the value of a displaced firm approaches $\infty$ when $r+d \rightarrow 0$. From this large base, an increase in the value of a displaced firm caused by an increase in $y$ is a negligible proportional increase.

To summarize, capital liquidity, capital reallocation, capital creation and firm values are all procyclical in the equilibrium, but whether a firm's $q$ is procyclical or counter cyclical depends on the persistence of aggregate productivity and the location of the firm in the value distribution. When aggregate productivity is sufficiently persistent, $q$ is procyclical for a low-value firm and counter cyclical for a high-value firm. In this case, the spread in $q$ is counter cyclical. When aggregate productivity is not persistent, $q$ is counter cyclical for a low-value firm and procyclical for a high-value firm. In this case, the spread in $q$ is procyclical. In both cases, the mean and the standard deviation in $q$ across firms can be procyclical, counter cyclical or acyclical. 
These predictions of the model can be checked in the data. ${ }^{14}$ For example, we can divide firms in the data into quintiles according to the market value and test how $q$ in each quintile varies over the business cycle. Since aggregate productivity is highly persistent in the data, the above proposition implies that a firm's $q$ is more likely to be procyclical when the firm is closer to the lowest quintile and more likely to be counter cyclical when the firm is closer to the highest quintile. Moreover, the fraction of high-value firms in the economy is procyclical. However, the cyclical features of the mean and the standard deviation in $q$ across firms are ambiguous.

\section{Heterogeneous Productivity}

In the baseline model, all productive firms have the same productivity and, hence, the same value and the same $q$. In this section we introduce firm-specific productivity to generate heterogeneity across productive firms. The main purpose is to demonstrate that even for a productive firm, whether $q$ is procyclical or counter cyclical depends on the firm's location in the value distribution. In addition, we can examine how dispersion in $q$ across productive firms varies with aggregate productivity.

A productive firm's output flow is now $y+z$, where $z$ is firm-specific productivity. After buying or making capital, a firm is called a new firm at the end of the period. ${ }^{15}$ Such a firm enters the next period and draws $z$ from the interval $\left[z_{L}, z_{H}\right]$ according to a cumulative distribution function $G$. Precisely, $z$ will be realized for a new firm at the time when next period's $y$ will be realized. The mean of $z$ is zero. The realization of $z$ for a firm will remain the same as long as the firm retains this unit of capital. In bargaining, since the two sides do not know $z$ that the buyer of capital will have, they use the expected value of $z$ to calculate the surplus of a trade. Similarly, when choosing whether to create capital, a capital maker does not know $z$ and uses the expected value of $z$ to calculate the value of making capital. This assumption of timing not only simplifies the analysis, but also

\footnotetext{
${ }^{14}$ We plan to add this empirical work later.

${ }^{15}$ As cautioned earlier, a new firm in this model should not be literally interpreted as a new firm in the data. Instead, a new firm can be a new unit of capital that an existing firm acquires or makes, but the firm treats each unit of capital separately.
} 
captures the realism that a firm must have capital in place before knowing how productive the capital is for the firm. ${ }^{16}$

After the realization of $z$, a firm can in principle choose whether to sell capital or to use capital to produce. If $z$ is sufficiently low, the value of selling capital can be higher than using capital to produce. This endogenous exit from productive firms introduces an additional dimension in which dispersion in $q$ can vary with aggregate productivity. Specifically, because the cut-off productivity below which a productive firm chooses to sell capital is likely to vary with aggregate productivity, the distribution of productivity across productive firms is endogenous and varies with aggregate productivity. Although this additional dimension is interesting, it is intractable in the stochastic equilibrium because the endogenous distribution of firms over productivity is a state variable with a large dimension. Appendix D analyzes the steady state with such endogenous exit. For the stochastic equilibrium, we rule out such endogenous exit by assuming that $z_{L}$ is sufficiently high in the sense given by (5.8) in Proposition 5.1 below.

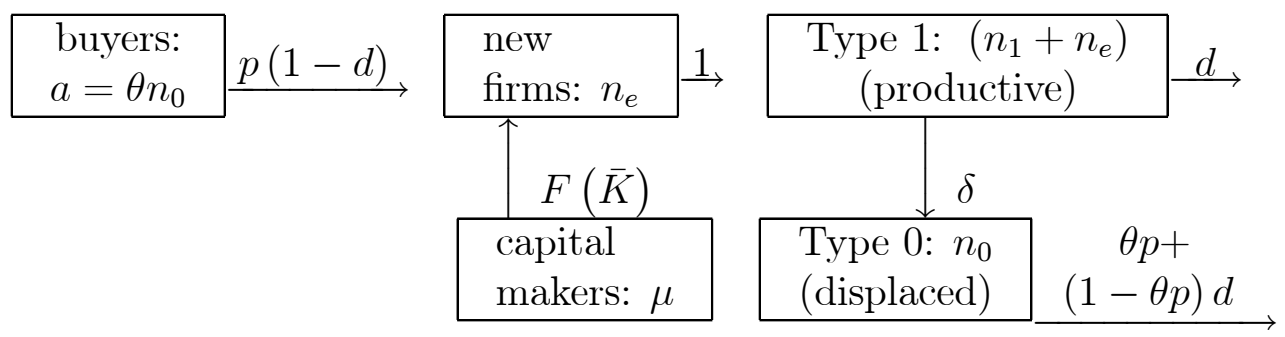

At the end of a period or, equivalently, at the beginning of the next period before $z$ is realized, there are three types of firms indexed by $j \in\{1,0, e\}$, where $e$ indicates a new firm. As described above, a new firm is a firm that either bought capital and escaped depreciation or made capital in the current period. Different from a type- 1 firm, a new firm has not received the realization of $z$. The measure of type- $j$ firms at the end of a period is denoted $n_{j,+1}$. Because all new firms at the beginning of a period become type-1 after the realization of $z$, the measure of productive firms is $\left(n_{1}+n_{e}\right)$. The flows of firms

\footnotetext{
${ }^{16}$ An alternative assumption is that a new firm must produce for a period before receiving the realization of $z$. The difference between this assumption and one used in the analysis is only minor because, in both cases, a new firm has already paid the price or the cost of capital before $z$ is realized.
} 
depicted above generate the following dynamics in the distribution of firms:

$$
\begin{aligned}
& n_{1,+1}-n_{1}=n_{e}-(\delta+d)\left(n_{1}+n_{e}\right) \\
& n_{0,+1}-n_{0}=\delta\left(n_{1}+n_{e}\right)-[\theta p+(1-\theta p) d] n_{0} \\
& n_{e,+1}=(1-d) \theta p n_{0}+\mu F(\bar{K}) .
\end{aligned}
$$

All value functions are measured at the end of a period. The value is $V_{0}(y)$ for a displaced firm, $V_{e}(y)$ for a new firm, and $V_{1}(y, z)$ for a productive firm with firm-specific productivity $z$. Under (5.8), it is optimal for a productive firm to produce rather than sell capital. Since all productive firms face the same probability of displacement and the same probability of depreciation, the firms exiting from the productive group are randomly selected from the group. As a result, the distribution over $z$ across productive firms that escape displacement and depreciation is the same as the distribution across productive firms before these shocks. Since this distribution does not change over time, it remains the same as $G$, the distribution according to which a new firm draws firm-specific productivity. Therefore, the value of a new firm, $V_{e}(y)$, is also the mean of the values of type- 1 firms. That is,

$$
V_{e}(y)=\int V_{1}(y, z) \mathrm{d} G(z) .
$$

In contrast to the baseline economy, a capital maker becomes a new firm rather than a type-1 firm. A capital maker chooses to make capital if and only if the cost of making capital is lower than the value of a new firm. Thus, the cut-off cost below which a capital maker chooses to make capital is

$$
\bar{K}(y)=V_{e}(y)
$$

Similarly, if a buyer who just bought capital escapes depreciation, the value is $V_{e}$ rather than $V_{1}$. Competitive entry of buyers into the market yields

$$
p(\theta)\left[(1-d) V_{e}-m\right]=\psi
$$

The Bellman equations of $\left(V_{0}, V_{1}\right)$ are:

$$
\begin{aligned}
& (1+r) V_{0}(y)=\mathbb{E}\left\{\theta_{+1} p\left(\theta_{+1}\right)\left[m\left(y_{+1}\right)-(1-d) V_{0}\left(y_{+1}\right)\right]+(1-d) V_{0}\left(y_{+1}\right)\right\} \\
& (1+r) V_{1}(y, z)=\mathbb{E}\left\{y_{+1}+z+(1-\delta-d) V_{1}\left(y_{+1}, z\right)+\delta V_{0}\left(y_{+1}\right)\right\}
\end{aligned}
$$


The equation for $V_{0}$ is the same as (2.4), and the equation for $V_{1}$ modifies (2.5) by incorporating firm-specific productivity. Note that $z$ is known in the above equation for $V_{1}$. Because the value for a buyer after buying capital is $(1-d) V_{e}$ and the value for a seller after failing to trade is $(1-d) V_{0}$, the joint surplus of a match is $(1-d)\left(V_{e}-V_{0}\right)$. Nash bargaining determines the price of capital as

$$
m=(1-d)\left[\sigma V_{e}+(1-\sigma) V_{0}\right]
$$

Denote $\Delta(y, z)=V_{1}(y, z)-V_{0}(y), \Delta_{e}(y)=V_{e}(y)-V_{0}(y)$, and $q_{j}=V_{j} / m$, where $j \in\{1,0, e\}$. It is clear from (5.1) that

$$
\Delta_{e}(y)=\int \Delta(y, z) \mathrm{d} G(z), \quad q_{e}(y)=\int q_{1}(y, z) \mathrm{d} G(z) .
$$

With (5.5), the free-entry condition of buyers (5.3) becomes $\theta=\theta\left(\Delta_{e}\right)$, where the function $\theta($.$) is defined in (3.2). Note that \Delta_{e}, \theta, m, \bar{K}, V_{e}$ and $q_{e}$ are all functions of $y$ and independent of $z$. As in Proposition 3.1, these functions and $\left(V_{1}, \Delta\right)$ are independent of $n$. Subtracting the two equations in (5.4) and substituting $\theta=\theta\left(\Delta_{e}\right)$ yields

$$
\Delta(y, z)=\frac{1}{1+r} \mathbb{E}\left[y_{+1}+z+(1-\delta-d) \Delta\left(y_{+1}, z\right)-\frac{\sigma \psi}{1-\sigma} \theta\left(\Delta_{e}\left(y_{+1}\right)\right)\right] .
$$

Integrating over $z$, and setting the unconditional mean of $z$ to 0 , we get

$$
\Delta_{e}(y)=\frac{1}{1+r} \mathbb{E}\left[y_{+1}+(1-\delta-d) \Delta_{e}\left(y_{+1}\right)-\frac{\sigma \psi}{1-\sigma} \theta\left(\Delta_{e}\left(y_{+1}\right)\right)\right] .
$$

Notice that (5.7) becomes identical to (3.3) if $\Delta_{e}$ is replaced with $\Delta$. Exploring this observation, we prove the following proposition in Appendix C:

Proposition 5.1. Under the same assumptions as in Proposition 3.1, (5.7) has a unique solution $\Delta_{e}(y)$ which is strictly increasing in $y$. The unique solution to (5.6) is $\Delta(y, z)=$ $\Delta_{e}(y)+\frac{z}{r+\delta+d}$. Thus, $\left(\theta, m, V_{0}, V_{e}, \bar{K}\right)(y)$ and $V_{1}(y, z)$ are strictly increasing functions, and $V_{1}(y, z)=V_{e}(y)+\frac{z}{r+\delta+d}$. Moreover, if

$$
z_{L} \geq-\mathbb{E}\left[y_{+1}-\frac{\sigma \psi}{1-\sigma} \theta\left(\Delta_{e}\left(y_{+1}\right)\right)\right]
$$


then $\Delta(y, z) \geq 0$ for all $(y, z)$, and so all productive firms indeed choose to produce rather than sell capital. All results for $\left(q_{1}, q_{0}\right)$ in section 4 are now valid for $\left(q_{e}, q_{0}\right)$ and, in particular, $q_{e}$ and $q_{0}$ have opposite cyclical features. Furthermore, if $q_{e}^{\prime}(y)$ is close to zero (including zero), there exists $z_{c} \in\left(z_{L}, z_{H}\right)$ such that $\frac{\partial}{\partial y} q_{1}(y, z)>0$ if and only if $z<z_{c}$. Regardless of the sign of $q_{e}^{\prime}(y)$, an increase in $y$ reduces $\left[q_{1}\left(y, z_{H}\right)-q_{e}(y)\right]$, $\left[q_{e}(y)-q_{1}\left(y, z_{L}\right)\right]$, and the standard deviation in $q_{1}(y, z)$ across $z$.

In this economy with firm-specific productivity, the value of a displaced firm behaves in exactly the same way as in the economy with homogeneous productivity. The value of a new firm that has not received the realization of firm-specific productivity behaves in exactly the same way as the value of a productive firm in the economy with homogeneous productivity. Thus, $\left(q_{e}, q_{0}\right)$ in the economy with firm-specific productivity have the same characteristics as $\left(q_{1}, q_{0}\right)$ in the economy with homogeneous productivity. Because a buyer's entry decision is based on the value of a new firm, which is procyclical, capital market liquidity is procyclical as in the economy with homogeneous productivity. So are the price of capital and the cut-off cost $\bar{K}$ for capital creation.

We have explained above that the mean of the values of old productive firms is equal to the value of a new firm. The mean of $q$ across old productive firms is then equal to $q_{e}$, a new firm's $q$. Because $q_{e}$ behaves in the same way as $q_{1}$ in the economy with homogeneous productivity, the mean of $q$ across productive firms with heterogeneous productivity responds ambiguously to aggregate productivity. Recall that when aggregate productivity is sufficiently persistent, $q_{1}$ in the economy with homogeneous productivity is counter cyclical (see Proposition 4.4). In this case, the mean of $q$ across productive firms with heterogeneous productivity is counter cyclical. The mean of $q$ across all firms, including displaced firms, has ambiguous cyclicality even when aggregate productivity is persistent.

With a non-degenerate distribution of productivity across productive firms, the above proposition makes a precise statement about how the cyclical feature of $q$ of a productive firm depends on where the firm lies in the value distribution. If the $q$ of a firm at the mean productivity is acyclical, then all productive firms below the mean productivity have 
procyclical $q$, and all productive firms above the mean productivity have counter cyclical $q$. This is because the deviation of a firm's productivity from the mean is acyclical. As the price of capital is procyclical, the ratio of this deviation to the price of capital is procyclical if and only if the deviation is negative. This result extends to the case where the $q$ of a firm at the mean productivity is not strongly cyclical or strongly counter cyclical. In this case, there exists a cut-off on firm-specific productivity such that a productive firm's $q$ is procyclical if and only if the firm's specific productivity is below this cutoff.

Since an increase in aggregate productivity increases low-productivity firms' $q$ and decreases high-productivity firms' $q$, it reduces the spread in $q$ across the firms in the top half of productivity, reduces the spread in $q$ across the firms in the bottom half of productivity, and reduces the standard deviation in $q$ across all productive firms. Thus, procyclical liquidity, procyclical reallocation of capital across firms and procyclical capital creation are consistent with counter cyclical dispersion in $q$ across productive firms. As in section 4, the cyclical feature of dispersion in $q$ across all firms, including displaced firms, is ambiguous. Depending on the relative measure of displaced firms to productive firms, overall dispersion in $q$ can be counter cyclical, acyclical or weakly procyclical.

\section{Concluding Remarks}

By analyzing a stochastic equilibrium with endogenous liquidity in the capital market, this paper explains the puzzling fact that capital reallocation across firms is procyclical while dispersion in Tobin's $q$ across firms is acyclical or counter cyclical. Capital is reallocated across firms through a frictional market modeled by search and matching. The market tightness captures liquidity in this market and is endogenously determined as buyers choose whether to enter the market. Capital creation is also endogenous as capital makers choose whether to incur a cost to make capital. When aggregate productivity increases, more capital is created. At the same time, more buyers enter the capital market to buy capital in an attempt to capture the increased value of a productive firm. As a result, market liquidity increases and more capital is reallocated. The price of capital increases, which 
increases $q$ of low-value firms and reduces $q$ of high-value firms. The mean and standard deviation in $q$ across firms respond ambiguously to an increase in aggregate productivity. These results are robust to the addition of heterogeneity in firm-specific productivity.

By generating endogenously procyclical liquidity of the capital market, the model in this paper can be useful also for accounting for the behavior of asset prices. Specifically, since market liquidity varies in the same direction as aggregate output, it increases the riskiness of the market portfolio of assets. As a result, endogenously procyclical liquidity of the capital market increases the equity premium of the market portfolio. In a future research project, we plan to investigate how much this mechanism can account for the equity premium puzzle documented by Mehra and Prescott (1985). 


\section{Appendix}

\section{A. Proof of Proposition 3.1}

Write $(3.3)$ as $\Delta(n, y)=(T \Delta)(n, y)$, where $T$ denotes the following mapping:

$$
\begin{aligned}
& (T \Delta)(n, y) \\
& =\frac{1}{1+r} \int\left[y_{+1}+(1-\delta-d) \Delta\left(n_{+1}, y_{+1}\right)-\frac{\sigma \psi}{1-\sigma} \theta\left(\Delta\left(n_{+1}, y_{+1}\right)\right)\right] \Phi\left(\mathrm{d} y_{+1}, y\right)
\end{aligned}
$$

The function $\Delta$ is a fixed point of $T$. We determine this fixed point in the functional space $(\mathcal{C},\|\|$.$) , where \mathcal{C}$ contains all continuous functions on $[0,1]^{2} \times Y$ and $\|$.$\| is the sup-norm.$ Since the sup-norm is presumed, we refer to this functional space as $\mathcal{C}$. We prove that under (3.4) and (3.5), $T$ is a monotone contraction on $\mathcal{C}$, and so $T$ has a unique fixed point in $\mathcal{C}$ (See Stokey, et al., 1989). For this purpose, we express (3.5) equivalently as

$$
\left|\theta\left(f_{1}\right)-\theta\left(f_{2}\right)\right| \leq(1-d)(1-\sigma) \frac{A}{\psi}\left|f_{1}-f_{2}\right| \text { for all } f_{1}, f_{2} \in \mathcal{C} .
$$

First, we verify that $T$ is a mapping from $\mathcal{C}$ to $\mathcal{C}$. Let $f$ be any element in $\mathcal{C}$. For any $\left(n_{a}, y_{a}\right)$ and $\left(n_{b}, y_{b}\right)$ in $[0,1]^{2} \times Y,($ A.2) implies

$$
\left|\theta\left(f\left(n_{a}, y_{a}\right)\right)-\theta\left(f\left(n_{b}, y_{b}\right)\right)\right| \leq(1-d)(1-\sigma) \frac{A}{\psi}\left|f\left(n_{a}, y_{a}\right)-f\left(n_{b}, y_{b}\right)\right| .
$$

By the definition of continuity, this implies that $\theta(f) \in \mathcal{C}$ whenever $f \in \mathcal{C}$. Thus, the expression in [.] in (A.1) is an element in $\mathcal{C}$. Because the transition function $\Phi$ is assumed to have the Feller property, then $T f \in \mathcal{C}$.

Second, we prove that $T$ is monotone. That is, letting $f_{1}$ and $f_{2}$ be arbitrary elements in $\mathcal{C}$ that satisfy $f_{1}(n, y) \geq f_{2}(n, y)$ for all $(n, y) \in[0,1]^{2} \times Y$, we prove that $\left(T f_{1}\right)(n, y) \geq$ $\left(T f_{2}\right)(n, y)$ for all $(n, y)$. Because $p^{-1}($.$) is a decreasing function, then \theta(f)$ is increasing in $f$. Condition (A.2) implies

$$
0 \leq \theta\left(f_{1}(n, y)\right)-\theta\left(f_{2}(n, y)\right) \leq(1-d)(1-\sigma) \frac{A}{\psi}\left[f_{1}(n, y)-f_{2}(n, y)\right] .
$$

With the definition of $T$, we have

$$
\left(T f_{1}-T f_{2}\right)(n, y) \geq \frac{1-\delta-d-(1-d) \sigma A}{1+r} \int\left(f_{1}-f_{2}\right)\left(n_{+1}, y_{+1}\right) \Phi\left(\mathrm{d} y_{+1}, y\right)
$$

Since $f_{1} \geq f_{2},(3.4)$ implies that the right-hand side above is non-negative. Thus, $\left(T f_{1}\right)(n, y) \geq$ $\left(T f_{2}\right)(n, y)$, as desired. 
Third, we prove that $T$ has discounting. Let $f$ be an arbitrary element in $\mathcal{C}$ and $c \geq 0$ be an arbitrary real number. Let $(f+c)$ denote the function such that $(f+c)(n, y)=$ $f(n, y)+c$ for all $(n, y)$. Then, $(f+c) \in \mathcal{C}$. Moreover, since $f+c \geq f$, the above proof of monotonicity of $T$ implies that $T(f+c) \geq T f$ and $\theta((f+c)(n, y))-\theta(f(n, y)) \geq 0$. Thus,

$$
[T(f+c)-T f](n, y) \leq \frac{1-\delta-d}{1+r} c \int \Phi\left(\mathrm{d} y_{+1}, y\right)=\frac{1-\delta-d}{1+r} c .
$$

Because $0<\frac{1-\delta-d}{1+r}<1$, this shows that $T$ has discounting.

The three properties of $T$ above imply that $T$ satisfies Blackwell's sufficient conditions for a monotone contraction mapping on $\mathcal{C}$ and so, by the monotone contraction mapping theorem, $T$ has a unique fixed point $\Delta \in \mathcal{C}$ (see Stokey, et al., 1989). Then, the market tightness is uniquely determined by $\theta(\Delta)$, the value functions by (2.4) and (2.5), and $\bar{K}$ by (2.2). The equations in (3.1) yield:

$$
\begin{aligned}
& n_{1,+1}=\mu F(\bar{K})+(1-\delta-d) n_{1}+(1-d) \theta p n_{0} \\
& n_{0,+1}=\delta n_{1}+(1-\theta p)(1-d) n_{0} .
\end{aligned}
$$

Property (ii) below will show that $(\theta, \bar{K})$ are independent of $\left(n_{+1}, n\right)$. The above equations are then first-order, linear difference equations of $n=\left(n_{1}, n_{0}\right)$. Given any initial values of $n$ and any path of realizations of $y$, the above equations determine a unique path of $n$. Thus, the equilibrium is unique. Moreover, it can be verified that the coefficient matrix on $\left(n_{1}, n_{0}\right)$ on the right-hand side of the above equations has two eigenvalues in $(-1,1)$. Thus, the path of $n$ converges to a unique steady state if $y$ is constant.

To verify properties (i)-(iii) stated in the proposition, we explore the fact that the mapping $T$ is a monotone contraction. For property (i), note that for any $f \in \mathcal{C}$ that satisfies $f \geq \frac{\psi}{(1-d)(1-\sigma)}, T f$ satisfies:

$$
(T f)(n, y) \geq \frac{1}{1+r} \mathbb{E}\left[y_{+1}+\frac{(1-\delta-d) \psi}{(1-d)(1-\sigma)}\right]>\frac{\psi}{(1-d)(1-\sigma)} .
$$

The first inequality follows from the fact that $\left[(1-\delta-d) f-\frac{\sigma \psi}{1-\sigma} \theta(f)\right]$ is increasing in $f$. The second (strict) inequality follows from the assumption (2.1). Thus, $T$ maps functions that are greater than or equal to $\frac{\psi}{(1-d)(1-\sigma)}$ into functions that are strictly greater than $\frac{\psi}{(1-d)(1-\sigma)}$. Thus, the fixed point $\Delta$ satisfies $\Delta \geq \frac{\psi}{(1-d)(1-\sigma)}$. This implies $\Delta=T \Delta>$ $\frac{\psi}{(1-d)(1-\sigma)}$, and so $\theta=\theta(\Delta)>\theta\left(\frac{\psi}{(1-d)(1-\sigma)}\right)=p^{-1}(1)=0$.

For property (ii), notice that the right-hand side of (A.1) does not depend on $\left(n_{+1}, n\right)$ except possibly through $\Delta\left(n_{+1}, y_{+1}\right)$. Because the law of motion of $y_{+1}$ is independent of $\left(n_{+1}, n\right)$, the right-hand side of (A.1) is independent of $\left(n_{+1}, n\right)$ if $\Delta\left(n_{+1}, y_{+1}\right)$ is so. Starting with any function $f$ independent of $n, T f$ is independent of $n$. The sequence 
of functions obtained by applying $T$ on $f$ repeatedly converges to a fixed point, $\Delta(y)$, that is independent of $n$. Because $T$ is a monotone contraction, even if one starts with any function $\tilde{f}$ that depends on $n$, the sequence of functions obtained by applying $T$ on $\tilde{f}$ repeatedly converges to the unique fixed point $\Delta(y)$ just obtained.

For property (iii), let $\mathcal{C}_{y}$ be the set that contains all continuous functions on $Y$. Let $\mathcal{C}_{I}$ be the subset of $\mathcal{C}_{y}$ that contains all increasing functions on $Y$, including weakly increasing functions. Let $f$ be an arbitrary element in $\mathcal{C}_{I}$, and temporarily denote

$$
B(y) \equiv y+(1-\delta-d) f(y)-\frac{\sigma \psi}{1-\sigma} \theta(f(y)) .
$$

Then, $(T f)(y)=\frac{1}{1+r} \int B\left(y_{+1}\right) \Phi\left(\mathrm{d} y_{+1}, y\right)$. Recall that $\Phi\left(y_{+1}, y\right)$ is assumed to be strictly increasing in $y$ (see Assumption 1). If $B($.$) is a strictly increasing function, then (T f)(y)$ is a strictly increasing function. That is, $T$ maps $\mathcal{C}_{I}$ into the subset of $\mathcal{C}_{I}$ that contains all strictly increasing functions on $Y$. Because $\mathcal{C}_{I}$ is a closed subset of $\mathcal{C}_{y}$, and because the fixed point of $T$ is unique, then the fixed point $\Delta$ lies in $\mathcal{C}_{I}$. Applying the mapping $T$ on this fixed point, we conclude that $\Delta(y)=(T \Delta)(y)$ is a strictly increasing function. To prove that $B($.$) is a strictly increasing function whenever f$ is (weakly) increasing, let $y_{1}$ and $y_{2}$ be arbitrary elements in $Y$, with $y_{1}>y_{2}$. Then, $f\left(y_{1}\right) \geq f\left(y_{2}\right)$. Similar to the above proof of monotonicity of $T$, we can prove that

$$
B\left(y_{1}\right)-B\left(y_{2}\right) \geq\left(y_{1}-y_{2}\right)+[1-\delta-d-(1-d) \sigma A]\left[f\left(y_{1}\right)-f\left(y_{2}\right)\right] .
$$

Because (3.4) implies that the second term on the right-hand side is non-negative, then $B\left(y_{1}\right)>B\left(y_{2}\right)$. Thus, $B($.$) is a strictly increasing function.$

For property (iv) in the proposition, it is clear from (3.2) that $\theta=\theta(\Delta(y))$ is a strictly increasing function of $y$ and independent of $n$. Substituting $m$ from (2.6) and $p$ from (2.3), (2.4) yields:

$$
V_{0}=\frac{1}{1+r} \mathbb{E}\left[\frac{\sigma}{1-\sigma} \psi \theta\left(\Delta\left(y_{+1}\right)\right)+(1-d) V_{0,+1}\right] .
$$

It is easy to verify that the right-hand side of this equation is a monotone contraction mapping of $V_{0}$ on $\mathcal{C}_{y}$. Thus, the equation has a unique fixed point $V_{0}(y)$, which depends on $y$ but not on $n$. Moreover, because $\theta(\Delta(y))$ is a strictly increasing function of $y$ and $\Phi\left(y_{+1}, y\right)$ is strictly increasing in $y$, the mapping defined by the right-hand side of the above equation maps (weakly) increasing functions into strictly increasing functions. Thus, the fixed point $V_{0}(y)$ is strictly increasing in $y$.

Because $\Delta(y)$ and $V_{0}(y)$ are both strictly increasing functions of $y$, it is clear that $V_{1}(y)=V_{0}(y)+\Delta(y)$ is a strictly increasing function of $y$ and independent of $n$. Then, by (2.6), $m(y)$ is a strictly increasing function of $y$ and independent of $n$. Since $\bar{K}(y)=V_{1}(y)$, and $V_{1}(y)$ is an increasing function, $\bar{K}(y)$ is an increasing function. QED 


\section{B. Proof of Proposition 4.4}

We verify that $\Delta(y)$ and $V_{0}(y)$ in (4.7) satisfy the functional equations in (4.6). Because these functional equations have unique solutions, as proven in Appendix A, then $\Delta(y)$ and $V_{0}(y)$ in (4.7) are the only solutions. Substituting $\Delta$ from (4.7) and $\mathbb{E} y_{+1}$ from (4.5) into the functional equation for $\Delta$ in (4.6), we can verify that the functional equation is indeed satisfied if and only if

$$
\begin{aligned}
& b_{1}=\frac{\rho}{1+r-\rho[(1-d)(1-\sigma)-\delta]} \\
& b_{0}=\frac{1}{r+\delta+d+\sigma(1-d)}\left[\frac{\sigma \psi}{1-\sigma}+\frac{(1+r)(1-\rho) y^{*}}{1+r-\rho[(1-d)(1-\sigma)-\delta]}\right] .
\end{aligned}
$$

Similarly, substituting $\left(V_{0}, \Delta\right)$ from (4.7) and $\mathbb{E} y_{+1}$ from (4.5) into the functional equation for $V_{0}$ in (4.6), we can verify that the functional equation is indeed satisfied if and only if

$$
\begin{aligned}
& c_{1}=\frac{(1-d) \sigma \rho b_{1}}{1+r-\rho(1-d)} \\
& c_{0}=\frac{\sigma}{r+d}\left[(1-d)\left(b_{0}+\frac{(1+r)(1-\rho) b_{1} y^{*}}{1+r-\rho(1-d)}\right)-\frac{\psi}{1-\sigma}\right] .
\end{aligned}
$$

By Corollary 4.1, $q_{0}^{\prime}(y)>0$ if and only if $\frac{V_{0}(y)}{\Delta(y)}$ is an increasing function of $y$. With the above solutions for the functions $\Delta(y)$ and $V_{0}(y)$, it is easy to see that $\frac{V_{0}(y)}{\Delta(y)}$ is an increasing function of $y$ if and only if $c_{1} b_{0}-b_{1} c_{0}>0$. In turn, $\left(c_{1} b_{0}-b_{1} c_{0}\right)$ has the same sign as the following expression:

$$
1-(1-\rho)\left\{\frac{(1-d)(1-\sigma) \frac{y^{*}}{\psi}-r-\delta-d}{[r+\delta+d+\sigma(1-d)](r+d) /(1+r)}+1\right\} .
$$

Under the maintained assumption $y^{*}>\frac{(r+\delta+d) \psi}{(1-d)(1-\sigma)}$, the coefficient of $(1-\rho)$ in $\{$.$\} is positive.$ Thus, the above expression is positive if and only if

$$
\rho>\underline{\rho} \equiv\left[\frac{[r+\delta+d+\sigma(1-d)](r+d) /(1+r)}{(1-d)(1-\sigma) \frac{y^{*}}{\psi}-r-\delta-d}+1\right]^{-1} .
$$

The maintained assumption $y^{*}>\frac{(r+\delta+d) \psi}{(1-d)(1-\sigma)}$ implies $\underline{\rho} \in(0,1)$. Moreover, $\underline{\rho} \rightarrow 0$ when $y^{*} \rightarrow \frac{(r+\delta+d) \psi}{(1-d)(1-\sigma)}$. It is clear that $\underline{\rho} \rightarrow 1$ when $r+d \rightarrow 0$. QED

\section{Proof of Proposition 5.1}

The functional equation, (5.7), is the same as (A.1) except that $\Delta$ is replaced by $\Delta_{e}$. Thus, under the same assumptions as in Proposition 3.1, there exists a unique solution, $\Delta_{e}(y)$, to (5.7). This solution is a strictly increasing function of $y$, which implies that 
$\left(\theta, V_{0}, V_{e}, \bar{K}, m\right)(y)$ are strictly increasing functions of $y$. By subtracting (5.7) from (5.6), we get

$$
\Delta(y, z)-\Delta_{e}(y)=\frac{1}{1+r}\left\{z+(1-\delta-d) \mathbb{E}\left[\Delta\left(y_{+1}, z\right)-\Delta_{e}\left(y_{+1}\right)\right]\right\} .
$$

The mapping defined by the right-hand side of (C.1) is clearly a monotone contraction of the function $\left(\Delta-\Delta_{e}\right)$. Thus, there exists a unique solution for $\left[\Delta(y, z)-\Delta_{e}(y)\right]$. Moreover, since the right-hand side of (C.1) is independent of $y$, given $\left(\Delta-\Delta_{e}\right)$, and is strictly increasing in $z$, then the (unique) solution for $\left[\Delta(y, z)-\Delta_{e}(y)\right]$ is independent of $y$ and strictly increasing in $z$. In fact, we can verify that the unique solution to (C.1) is

$$
\Delta(y, z)-\Delta_{e}(y)=\frac{z}{r+\delta+d}
$$

Therefore, $\Delta(y, z)=\Delta_{e}(y)+\frac{z}{r+\delta+d}$ is strictly increasing in $(y, z)$. Because $V_{1}(y, z)-$ $V_{e}(y)=\Delta(y, z)-V_{e}(y)$, then $V_{1}(y, z)=V_{e}(y)+\frac{z}{r+\delta+d}$, which is strictly increasing in $(y, z)$.

Because $\Delta(y, z)$ is strictly increasing in $z, \Delta(y, z) \geq 0$ for all $(y, z)$ if and only if $\Delta\left(y, z_{L}\right) \geq 0$ for all $y$. This condition can be rewritten as $\Delta\left(y, z_{L}\right)-\Delta_{e}(y) \geq-\Delta_{e}(y)$ for all $y$. If

$$
\Delta_{e}(y)+\frac{1}{1+r}\left[z_{L}-(1-\delta-d) \mathbb{E} \Delta_{e}\left(y_{+1}\right)\right] \geq 0,
$$

then the right-hand side of (C.1) with $z=z_{L}$ maps any difference $\Delta\left(y_{+1}, z_{L}\right)-\Delta_{e}\left(y_{+1}\right) \geq$ $-\Delta_{e}\left(y_{+1}\right)$ into a difference $\Delta\left(y, z_{L}\right)-\Delta_{e}(y) \geq-\Delta_{e}(y)$. In this case, the fixed point of (C.1) at $z=z_{L}$ satisfies $\Delta\left(y, z_{L}\right)-\Delta_{e}(y) \geq-\Delta_{e}(y)$, i.e., $\Delta\left(y, z_{L}\right) \geq 0$. After substituting $\Delta_{e}(y)$ from (5.7), the above sufficient condition for $\Delta\left(y, z_{L}\right) \geq 0$ is equivalent to (5.8). Note that the right-hand of (5.8) is independent of $z$, and so the condition indeed provides a lower bound on $z_{L}$.

The equations for $\left(\Delta_{e}, V_{0}\right)$ are the same as the equations for $\left(\Delta, V_{0}\right)$ in the economy with homogeneous productivity. Also, the price of capital is given by (5.5), which is the same as (2.6) except replacing $V_{1}$ with $V_{e}$. Thus, the equations for $\left(q_{e}, q_{0}\right)$ are the same as those for $\left(q_{1}, q_{0}\right)$ in the economy with homogeneous productivity. All results for $\left(q_{1}, q_{0}\right)$ in section 4 are valid for $\left(q_{e}, q_{0}\right)$. In particular, the cyclical features of $q_{e}$ and $q_{0}$ are opposite because $\frac{1}{1-d}=\sigma q_{e}+(1-\sigma) q_{0}$ by $(5.5)$. For $q_{1}$, we use $V_{1}(y, z)=V_{e}(y)+\frac{z}{r+\delta+d}$ to compute

$$
q_{1}(y, z)=q_{e}(y)+\frac{z / m(y)}{r+\delta+d}
$$

Since the unconditional mean of $z$ is zero, $0 \in\left(z_{L}, z_{H}\right)$. Since $m^{\prime}(y)>0$, then $\left(\frac{z}{m(y)}\right)_{y}^{\prime}>0$ if and only if $z<0$. If $q_{e}^{\prime}(y)=0$, then $\frac{\partial}{\partial y} q_{1}(y, z)>0$ if and only if $z<0$. By continuity, if 
$q_{e}^{\prime}(y)$ is close to 0 , there exists $z_{c} \in\left(z_{L}, z_{H}\right)$ such that $\frac{\partial}{\partial y} q_{1}(y, z)>0$ if and only if $z<z_{c}$. Finally, because

$$
\begin{aligned}
& q_{1}\left(y, z_{H}\right)-q_{e}(y)=\frac{z_{H} / m(y)}{r+\delta+d}>0 \\
& q_{e}(y)-q_{1}\left(y, z_{L}\right)=-\frac{z_{L} / m(y)}{r+\delta+d}>0,
\end{aligned}
$$

both differences are decreasing functions of $y$, regardless of the sign of $q_{e}^{\prime}(y)$. If $S_{z}$ is the standard deviation in $z$, then the standard deviation in $q_{1}(y, z)$ across $z$ is $\frac{S_{z} / m(y)}{r+\delta+d}$, which is a decreasing function of $y$. QED

\section{Endogenous Exit from Productive Firms}

In section 5 we imposed the restriction (5.8) on the lower bound on firm-specific productivity so that all productive firms choose to produce rather than sell capital. In this appendix we eliminate this restriction. As a result, firms with sufficiently low $z$ choose to exit from the productive group and sell capital. We examine how this endogenous exit responds to changes in aggregate productivity. As explained in section 5, the stochastic equilibrium with such endogenous exist from productive firms is intractable. Thus, we focus on the deterministic steady state and conduct comparative statics with respect to $y^{*}$. To avoid trivial cases, we assume $z_{L}>-y^{*}$ so that output is positive for all realizations of $z$.

A productive firm chooses whether to produce or sell capital immediately after $z$ is realized. In the steady state, only new firms may find it optimal to sell capital, because old productive firms have already made this choice and decided to remain in the productive group. Once a firm chooses to sell capital, it loses the ability to produce regardless of whether the firm succeeds in selling capital. This assumption simplifies the analysis by eliminating the possibility that changes in $y$ induce marginal firms to go back and forth between selling capital and producing. A justification for the assumption is that once a firm ceases to produce, reviving production has a sufficiently high cost. With this assumption, a firm that chooses to sell capital is the same as a displaced firm and can be labeled as an endogenously displaced firm.

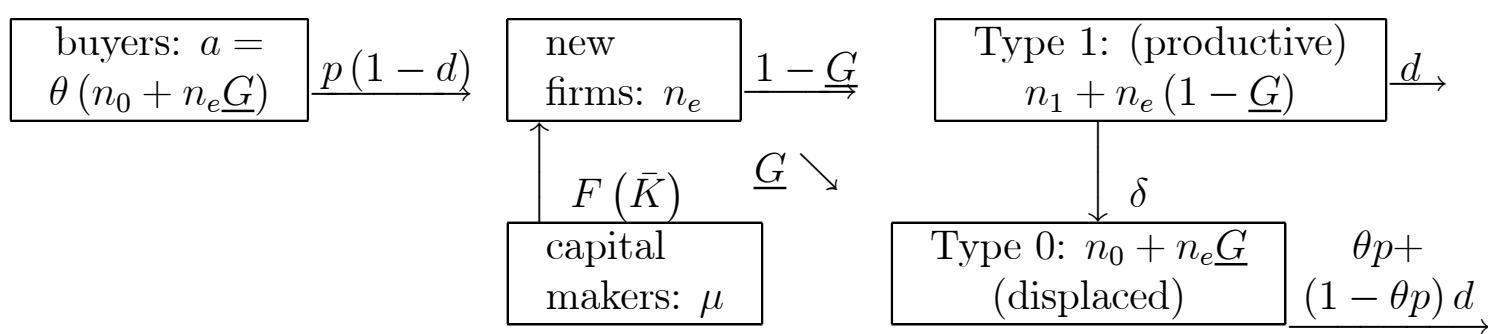

Let $\underline{z}(y)$ be the cutoff on firm-specific productivity below which a new firm chooses to sell capital. For a new firm, the probability of exiting into the displaced group is 
$\underline{G}(y) \equiv G(\underline{z}(y))$ and the probability of becoming type- 1 is $1-\underline{G}$. The measure of capital sellers in the market is $\left(n_{0}+n_{e} \underline{G}\right)$. The market tightness is now $\theta=a /\left(n_{0}+n_{e} \underline{G}\right)$, which yields $a=\theta\left(n_{0}+n_{e} \underline{G}\right)$. The measure of firms that produce in a period is $\left[n_{1}+n_{e}(1-\underline{G})\right]$. The flows of firms are depicted above. The distribution of firms at the end of the current period, indicated by the subscript +1 , obeys the following equations:

$$
\begin{aligned}
& n_{1,+1}-n_{1}=n_{e}(1-\underline{G})-(\delta+d)\left[n_{1}+n_{e}(1-\underline{G})\right] \\
& n_{0,+1}-n_{0}=n_{e} \underline{G}+\delta\left[n_{1}+n_{e}(1-\underline{G})\right]-[\theta p+(1-\theta p) d]\left(n_{0}+n_{e} \underline{G}\right) \\
& n_{e,+1}=(1-d) \theta p\left(n_{0}+n_{e} \underline{G}\right)+\mu F(\bar{K}) .
\end{aligned}
$$

In the steady state, the distribution of firms is constant over time, and so the above equations yield:

$$
\begin{aligned}
& n_{1}=\left(\frac{1}{\delta+d}-1\right)(1-\underline{G}) n_{e}, \quad n_{0}=\frac{(1-\theta p)(1-d) \underline{G}+\frac{\delta}{\delta+d}(1-\underline{G})}{\theta p+(1-\theta p) d} n_{e} \\
& n_{e}=\mu F(\bar{K})\left(\frac{\delta}{d}+1\right) \frac{\theta p+(1-\theta p) d}{\delta+d+\theta p(1-d)(1-\underline{G})} .
\end{aligned}
$$

These equations determine $\left(n_{1}, n_{0}, n_{e}\right)$ as functions of $(\bar{K}, \underline{z})$.

As in section 5 , the value at the end of a period is $V_{0}(y)$ for a displaced firm, $V_{e}(y)$ for a new firm, and $V_{1}(y, z)$ for a type- 1 firm with firm-specific productivity $z$. Because a new firm will choose to sell capital if and only if $z<\underline{z}$, the value of a new firm is

$$
V_{e}(y)=\underline{G} V_{0}(y)+\int_{z \geq \underline{z}} V_{1}(y, z) \mathrm{d} G(z) .
$$

With this new formula of $V_{e}(y)$ to replace (5.1), it is clear that the cut-off cost for making capital, $\bar{K}$, still satisfies (5.2), the free-entry condition of buyers is still (5.3), the Bellman equation for $V_{0}(y)$ is still the first equation in (5.4), and the price of capital still satisfies (5.5). However, $V_{1}(y, z)$ is meaningful only for $z \geq \underline{z}$, in which case $V_{1}(y, z)$ satisfies the second equation in (5.4). Use the same definition of $\Delta_{e}(y)=V_{e}(y)-V_{0}(y)$ but restrict the definition of $\Delta(y, z)=V_{1}(y, z)-V_{0}(y)$ to $z \geq \underline{z}$. Then, $\Delta(y, z)$ is given by (5.6) for $z \geq \underline{z}$, and $\Delta_{e}$ is related to $\Delta$ by

$$
\Delta_{e}(y)=\int_{z \geq \underline{z}} \Delta(y, z) \mathrm{d} G(z) .
$$

Since a new firm chooses to produce if and only if $V_{1}(y, z) \geq V_{0}(y)$, the cut-off $\underline{z}(y)$ solves:

$$
\Delta(y, \underline{z}(y))=0 .
$$

Define $q_{j}=V_{j} / m$ as in section 5 , where $j \in\{0,1, e\}$. Note that the mean of $q$ across productive firms is not equal to $q_{e}$, in contrast to section 5 . This is because the distribution of $z$ across productive firms is truncated below by $\underline{z}$. Precisely, the cumulative distribution function of $z$ across productive firms is $\frac{G(z)}{1-\underline{G}}$. The mean of $q$ across productive firms is

$$
q_{a}(y) \equiv \int_{z \geq \underline{z}(y)} q_{1}(y, z) \frac{\mathrm{d} G(z)}{1-\underline{G}(y)} .
$$

The following proposition holds: 
Proposition D.1. Focus on the deterministic steady state and maintain Assumption 1. A steady state with $\theta^{*}>0$ and $\underline{z}^{*} \in\left(z_{L}, z_{H}\right)$ exists if and only if $z_{L}$ is bounded above by the following condition:

$$
p\left(\frac{1-\sigma}{\sigma \psi}\left(y^{*}+z_{L}\right)\right)>\frac{\psi(r+\delta+d)}{(1-d)(1-\sigma)\left(-z_{L}\right)} .
$$

In the steady state, $\left(\Delta_{e}, V_{0}, V_{e}, \bar{K}, m\right)\left(y^{*}\right)$ increase in $y^{*},\left(\Delta^{*}, V_{1}^{*}\right)$ increase in $\left(y^{*}, z\right)$, and

$$
\frac{d \theta^{*}}{d y^{*}}>0, \quad \frac{d \underline{z}\left(y^{*}\right)}{d y^{*}}<0 .
$$

Moreover, $q_{0}^{\prime}\left(y^{*}\right)>0, q_{e}^{\prime}\left(y^{*}\right)<0$, and $q_{a}^{\prime}\left(y^{*}\right)<0$. There exists $z_{c} \in\left(\underline{z}^{*}, z_{H}\right)$ such that $q_{1}\left(y^{*}, z\right)$ increases in $y^{*}$ if and only if $z<z_{c}$. The spread and the standard deviation in $q$ across productive firms depend on $y^{*}$ ambiguously.

Proposition D.1 shows that the main results in the economy without endogenous exit of firms into the displaced group are robust to the allowance for such exit, at least in the deterministic steady state. In particular, the liquidity, the reallocation, and the creation of capital still increase in aggregate productivity, while the standard deviation in $q$ responds ambiguously to aggregate productivity. Across productive firms, an increase in aggregate productivity increases $q$ for relatively low value firms and reduces $q$ for relatively high value firms. However, because of the focus on the deterministic steady state, a new firm's $q$ and the mean of $q$ across productive firms both decrease in aggregate productivity.

The new result with endogenous exit into the displaced group is that an increase in aggregate productivity reduces the cut-off on firm-specific productivity above which a firm chooses to produce instead of selling capital. This effect is reminiscent of the sullying effect of an expansion or, equivalently, the flip side of the cleansing effect of a recession. This new effect implies that an increase in aggregate productivity extends the lower tail of the productivity distribution across productive firms. As a result, even among productive firms, the spread and the standard deviation in $q$ respond ambiguously to aggregate productivity.

\section{Proof of Proposition D.1:}

In the deterministic steady state, $\underline{z}^{*}=\underline{z}\left(y^{*}\right)$, and (5.6) becomes

$$
(r+\delta+d) \Delta\left(y^{*}, z\right)+\frac{\sigma \psi}{1-\sigma} \theta\left(\Delta_{e}\left(y^{*}\right)\right)=y^{*}+z \quad \text { for } z \geq \underline{z}^{*} .
$$

Subtracting this equation at $z=\underline{z}^{*}$ from this equation at an arbitrary $z \geq \underline{z}^{*}$, and using $\Delta\left(y^{*}, \underline{z}^{*}\right)=0$, we get:

$$
\Delta\left(y^{*}, z\right)=\frac{z-\underline{z}\left(y^{*}\right)}{r+\delta+d} \quad \text { for } z \geq \underline{z}^{*} .
$$


Integrating over $z \geq \underline{z}^{*}$ yields:

$$
\int_{z \geq \underline{z}^{*}}\left(z-\underline{z}^{*}\right) \mathrm{d} G(z)=(r+\delta+d) \Delta_{e}\left(y^{*}\right) .
$$

The left-hand side of (D.9) is a strictly decreasing function of $\underline{z}^{*}$. The value of this function is $-z_{L}$ at $\underline{z}^{*}=z_{L}$, and 0 at $\underline{z}^{*}=z_{H}$. Since $\Delta_{e}^{*}>0$, there is a unique solution $\underline{z}^{*} \in\left(z_{L}, z_{H}\right)$ if and only if

$$
\Delta_{e}\left(y^{*}\right)<\frac{-z_{L}}{r+\delta+d}
$$

Denote the solution to (D.9) for $\underline{z}^{*}$ as $\underline{z}\left(y^{*}\right)=\zeta\left(\Delta_{e}\left(y^{*}\right)\right)$. It is clear that $\zeta^{\prime}\left(\Delta_{e}^{*}\right)=$ $-\frac{r+\delta+d}{1-\underline{G}^{*}}<0$, where $\underline{G}^{*}=G\left(\underline{z}^{*}\right)$.

Setting $z=\underline{z}^{*}=\zeta\left(\Delta_{e}\left(y^{*}\right)\right)$ in (D.7) and using $\Delta\left(y^{*}, \underline{z}^{*}\right)=0$, we get:

$$
\frac{\sigma \psi}{1-\sigma} \theta\left(\Delta_{e}\left(y^{*}\right)\right)-\zeta\left(\Delta_{e}\left(y^{*}\right)\right)=y^{*}
$$

Since the left-hand side of (D.11) is a strictly increasing function of $\Delta_{e}^{*}$, for any given $y^{*}$ the solution to the equation for $\Delta_{e}^{*}$ is unique. We need $\Delta_{e}^{*}$ to satisfy (D.10). Note that $\zeta\left(\frac{-z_{L}}{r+\delta+d}\right)=z_{L}$. With the definition of $\theta($.$) in (3.2), the solution for \Delta_{e}^{*}$ to (D.11) satisfies (D.10) if and only if (D.5) is satisfied. Since $p($.$) is a strictly decreasing function, (D.5)$ implicitly determines an upper bound on $z_{L}$. That is, $z_{L}$ must be sufficiently low to ensure $\underline{z}^{*}>z_{L}$.

In addition, we need $\Delta_{e}\left(y^{*}\right)>\frac{\psi}{(1-d)(1-\sigma)}$ so that $\theta\left(\Delta_{e}\left(y^{*}\right)\right)>0$. With (D.11), this lower bound on $\Delta_{e}$ is equivalent to $\zeta\left(\frac{\psi}{(1-d)(1-\sigma)}\right)>-y^{*}$. Since $z_{L}>-y^{*}$, a sufficient condition for this lower bound on $\Delta_{e}$ is $\zeta\left(\frac{\psi}{(1-d)(1-\sigma)}\right) \geq z_{L}$. This sufficient condition is equivalent to that (D.9) becomes the inequality " $>$ " when $\underline{z}^{*}=z_{L}$ and $\Delta_{e}\left(y^{*}\right)=\frac{\psi}{(1-d)(1-\sigma)}$. It can be verified that this sufficient condition is (D.5) with the left-hand side being replaced by 1 and, hence, the condition is implied by (D.5). Therefore, (D.5) is necessary and sufficient for the steady state to satisfy $\underline{z}^{*} \in\left(z_{L}, z_{H}\right)$ and $\theta^{*}>0$.

Once $\left(\underline{z}^{*}, \Delta_{e}^{*}\right)$ are solved as above, we can solve other variables. $\Delta\left(y^{*}, z\right)$ is given by (D.8). The steady-state version of the first equation in (5.4) determines

$$
V_{0}\left(y^{*}\right)=\frac{\sigma(1-d)}{r+d} \theta^{*} p^{*} \Delta_{e}\left(y^{*}\right)
$$

where $p^{*}=p\left(\theta^{*}\right)$ and $\theta^{*}=\theta\left(\Delta_{e}\left(y^{*}\right)\right)$. The definitions of $\Delta_{e}$ and $\Delta$ imply

$$
\begin{aligned}
& V_{e}\left(y^{*}\right)=\left[1+\frac{\sigma(1-d)}{r+d} \theta^{*} p^{*}\right] \Delta_{e}\left(y^{*}\right) \\
& V_{1}\left(y^{*}, z\right)=\frac{z-\underline{z}\left(y^{*}\right)}{r+\delta+d}+\frac{\sigma(1-d)}{r+d} \theta^{*} p^{*} \Delta_{e}\left(y^{*}\right) \text { for } z \geq \underline{z}\left(y^{*}\right) .
\end{aligned}
$$


The cut-off cost for making capital is $\bar{K}\left(y^{*}\right)=V_{e}\left(y^{*}\right)$. The price of capital in (5.5) is

$$
m\left(y^{*}\right)=\sigma(1-d)\left[1+\frac{1-d}{r+d} \theta^{*} p^{*}\right] \Delta_{e}\left(y^{*}\right) .
$$

It is clear from (D.11) that $\Delta_{e}^{\prime}\left(y^{*}\right)>0$. Because $\theta^{*}=\theta\left(\Delta_{e}\left(y^{*}\right)\right)$ with $\theta^{\prime}\left(\Delta_{e}\right)>0$, and $\underline{z}\left(y^{*}\right)=\zeta\left(\Delta_{e}\left(y^{*}\right)\right)$ with $\zeta^{\prime}\left(\Delta_{e}\right)<0$, then $\theta^{*}$ increases in $y^{*}$ and $\underline{z}\left(y^{*}\right)$ decreases in $y^{*}$ as listed in (D.6). By (D.12) - (D.14) and $\bar{K}^{*}=V_{e}^{*}$, it is clear that $\left(V_{0}^{*}, V_{e}^{*}, \bar{K}^{*}, m^{*}\right)$ all increase in $y^{*}$. By (D.8) and (D.13), $\left(\Delta^{*}, V_{1}^{*}\right)$ increase in $\left(y^{*}, z\right)$.

With the definition $q_{j}=V_{j} / m$, where $j \in\{0,1, e\},(D .12)$ - (D.14) imply

$$
\begin{aligned}
& q_{0}\left(y^{*}\right)=\left(\frac{r+d}{\theta^{*} p^{*}}+1\right)^{-1}, q_{e}\left(y^{*}\right)=\frac{r+d+\sigma(1-d) \theta^{*} p^{*}}{\sigma(1-d)\left[r+d+(1-d) \theta^{*} p^{*}\right]}, \\
& q_{1}\left(y^{*}, z\right)=\frac{(r+d) R\left(y^{*}, z\right)+\sigma(1-d) \theta^{*} p^{*}}{\sigma(1-d)\left[r+d+(1-d) \theta^{*} p^{*}\right]} \\
& \text { where } R\left(y^{*}, z\right) \equiv \frac{z-\underline{z}\left(y^{*}\right)}{\int_{z \geq \underline{z}\left(y^{*}\right)}\left[z-\underline{z}\left(y^{*}\right)\right] \mathrm{d} G(z)} .
\end{aligned}
$$

We have used (D.9) to substitute $\Delta_{e}\left(y^{*}\right)$ in the calculation of $q_{1}$. Because $\theta p(\theta)$ is an increasing function of $\theta$, and $\mathrm{d} \theta^{*} / \mathrm{d} y^{*}>0$, it is easy to verify that $q_{0}^{\prime}\left(y^{*}\right)>0$ and $q_{e}^{\prime}\left(y^{*}\right)<0$.

For the response of $q_{1}$ to $y^{*}$, compute:

$$
\frac{\partial q_{1}\left(y^{*}, z\right)}{\partial y^{*}} \sim R_{y}^{\prime}\left(y^{*}, z\right)+\frac{(1-d)\left[\sigma-R\left(y^{*}, z\right)\right]}{r+d+(1-d) \theta^{*} p^{*}}\left[\theta^{*} p\left(\theta^{*}\right)\right]_{y}^{\prime}
$$

where $R_{y}^{\prime}=\frac{\partial R\left(y^{*}, z\right)}{\partial y^{*}},\left[\theta^{*} p\left(\theta^{*}\right)\right]_{y}^{\prime}=\frac{\mathrm{d}\left[\theta^{*} p\left(\theta^{*}\right)\right]}{\mathrm{d} y^{*}}$, and the symbol $\sim$ means having the same sign. We can verify that

$$
R_{y}^{\prime}\left(y^{*}, z\right) \sim-\underline{z}^{\prime}\left(y^{*}\right)\left[1-R\left(y^{*}, z\right)\right] \sim 1-R\left(y^{*}, z\right) .
$$

At $z=\underline{z}^{*}$, we have $R\left(y^{*}, \underline{z}^{*}\right)=0$ and $R_{y}^{\prime}\left(y^{*}, \underline{z}^{*}\right)>0$, which imply $\frac{\partial q_{1}\left(y^{*}, \underline{z}^{*}\right)}{\partial y^{*}}>0$. At $z=z_{H}$, we have $R\left(y^{*}, z_{H}\right)>\frac{1}{1-G^{*}}$ and $R_{y}^{\prime}\left(y^{*}, z_{H}\right)<0$, which imply $\frac{\partial q_{1}\left(y^{*}, z_{H}\right)}{\partial y^{*}}<0$. Moreover, the derivative of the right-hand side of (D.16) with respect to $z$ is

$$
\underline{z}^{\prime}\left(y^{*}\right)\left(1-\underline{G}^{*}\right)\left(R_{z}^{\prime}\right)^{2}-\frac{(1-d)\left[\theta^{*} p\left(\theta^{*}\right)\right]_{y}^{\prime}}{r+d+(1-d) \theta^{*} p^{*}} R_{z}^{\prime},
$$

where $R_{z}^{\prime}=\frac{\partial R\left(y^{*}, z\right)}{\partial z}$. It can be verified that $R_{z}^{\prime}>0$. Since $\underline{z}^{\prime}\left(y^{*}\right)<0$ and $\left[\theta^{*} p\left(\theta^{*}\right)\right]_{y}^{\prime}>0$, the above derivative is negative. That is, the right-hand side of (D.16) strictly decreases in $z$. Thus, there exists $z_{c} \in\left(\underline{z}^{*}, z_{H}\right)$ such that $\frac{\partial q_{1}\left(y^{*}, z\right)}{\partial y^{*}}>0$ if and only if $z<z_{c}$. Similar to section 5, a productive firm's $q$ increases in $y^{*}$ if and only if the firm's specific productivity is below a threshold, although the threshold is not zero.

With the expression for $q_{1}$ in (D.15), we can compute

$$
q_{a}\left(y^{*}\right)=\frac{\frac{r+d}{1-\underline{G}^{*}}+\sigma(1-d) \theta^{*} p^{*}}{\sigma(1-d)\left[r+d+(1-d) \theta^{*} p^{*}\right]} .
$$


It is clear that $q_{a}\left(y^{*}\right)>q_{e}\left(y^{*}\right)$. Also, $q_{a}^{\prime}\left(y^{*}\right)<0$. Two effects work in the same direction to generate $q_{a}^{\prime}\left(y^{*}\right)<0$. One is $\mathrm{d} \theta^{*} / \mathrm{d} y^{*}>0$ and the other other is $\underline{z}^{\prime}\left(y^{*}\right)<0$. As in section 5 , higher aggregate productivity increases capital market liquidity, which increases the price of capital by more proportionally than the average value of the firms in the existing group of productive firms. In addition, higher aggregate productivity reduces the cut-off $\underline{z}^{*}$ above which a new firm chooses to stay productive, which extends the lower tail of productivity across productive firms. This additional effect further reduces the magnitude in which the average value of productive firms increases in aggregate productivity and, hence, reduces the mean of $q$ across productive firms. In this sense, the endogenous exit of firms into the displacement group strengthens the outcome that the mean of $q$ across productive firms decreases in aggregate productivity.

The effects of higher aggregate productivity on $\theta^{*}$ and $\underline{z}^{*}$ work in opposite directions to affect the spread and the standard deviation in $q$ across productive firms. An increase in $\theta^{*}$ caused by a higher $y^{*}$ reduces the spread and the standard deviation in $q$ across productive firms. However, the reduction in the cut-off $\underline{z}^{*}$ caused by a higher $y^{*}$ widens the spread and the standard deviation in $q$ across productive firms. Which of these two effects dominates is ambiguous in general. QED 


\section{References}

[1] Abel, A.B. and O.J. Blanchard, 1986, "The Present Value of Profits and Cyclical Movements in Investment," Econometrica 54, 249-273.

[2] Cao, D., Lorenzoni, G. and K. Walentin, 2013, "Financial Frictions, Investment and Tobin's q," Manuscript, Georgetown University.

[3] Cao, M. and R. Wang, 2013, "Optimal CEO Compensation with Search: Theory and Empirical Evidence," Journal of Finance 68, 2001-2058.

[4] Cooper, R. and J. Ejarque, 2003, "Financial Frictions and Investment: Requiem in q," Review of Economic Dynamics 6, 710-728.

[5] Cui, W. and S. Radde, 2014, "Search-Based Endogenous Illiquidity and the Macroeconomy," Manuscript, University College London.

[6] Diamond, P.A., 1982, "Aggregate Demand Management in Search Equilibrium," Journal of Political Economy 90, 881-894.

[7] Duffie, D., Garleanu, N., and L.H. Pedersen, 2005, "Over-the-Counter Markets," Econometrica 73, 1815-1847.

[8] Eisfeldt, A.L., 2004, "Endogenous Liquidity in Asset Markets," Journal of Finance 59, $1-30$.

[9] Eisfeldt, A.L. and A.A. Rampini, 2006, "Capital Reallocation and Liquidity," Journal of Monetary Economics 53, 369-399.

[10] Fazzari, S., Hubbard, G. and B. Petersen, 1988, "Financing Constraints and Corporate Investment," Brooking Papers on Economic Activity 1, 141-195.

[11] Gilchrist, S. and C. Himmelberg, 1995, "Evidence on the Role of Cash Flow for Investment," Journal of Monetary Economics 36, 541-572.

[12] Gomes, J.F., 2001, "Financing Investment," American Economic Review 91, 1263 1285.

[13] Gould, J.P., 1968, "Adjustment Costs in the Theory of Investment of the Firm," Review of Economic Studies 35, 47-56.

[14] Hennessy, C. and T. Whited, 2007, "How Costly Is External Financing? Evidence from a Structural Estimation," Journal of Finance 62, 1705-1745.

[15] Jermann, U. and V. Quadrini, 2012, "Macroeconomic Effects of Financial Shocks," American Economic Review 102, 238-271.

[16] Kiyotaki, N. and J.H. Moore, 2012, "Liquidity, Business Cycles, and Monetary Policy," Manuscript, Princeton University.

[17] Lucas, R.E., Jr., 1967, "Adjustment Costs and the Theory of Supply," Journal of Political Economy 75, 321-334.

[18] Mehra, R. and E.C. Prescott, 1985, "The Equity Premium: A Puzzle," Journal of Monetary Economics 15, 145-161. 
[19] Mortensen, D.T., 1982, "Property Rights and Efficiency in Mating, Racing and Related Games," American Economic Review 72, 968-979.

[20] Pissarides, C.A., 1985, "Short-Run Equilibrium Dynamics of Unemployment, Vacancies and Real Wages," American Economic Review 75, 676-690.

[21] Ramey, V.A. and M.D. Shapiro, 2001, "Displaced Capital: A Study of Aerospace Plant Closings," Journal of Political Economy 109, 958-992.

[22] Sargent, T., 1980, "Tobin's q" and the Rate of Investment in General Equilibrium," Carnegie-Rochester Conference Series on Public Policy 12, 107-154. North-Holland.

[23] Shi, S., 1995, "Money and Prices: A Model of Search and Bargaining," Journal of Economic Theory 67, 467-496.

[24] Shi, S., 2013, "Liquidity, Asset and Business Cycles," forthcoming in Journal of Monetary Economics.

[25] Stokey, N., R.E. Lucas, Jr., with E.C. Prescott, 1989, Recursive Methods in Economic Dynamics, Cambridge, Massachusetts: Harvard University Press.

[26] Tobin, J., 1969, "A General Equilibrium Approach to Monetary Theory," Journal of Money, Credit and Banking 1, 15-29.

[27] Trejos, A. and R. Wright, 1995, "Search, Bargaining, Money and Prices," Journal of Political Economy 103, 118-141.

[28] Yang, Z., 2014, "Search, Asset Liquidity and Business Cycles," Manuscript, Queen's University. 